\title{
Gradient reconstitution of membrane proteins for solid-state NMR studies
}

\author{
Denis Lacabanne ${ }^{1}$, Alons Lends ${ }^{2}$, Clément Danis ${ }^{1}$, Britta Kunert ${ }^{1}$, Marie-Laure Fogeron ${ }^{1}$, Vlastimil \\ Jirasko $^{2}$, Claire Chuilon ${ }^{1}$, Lauriane Lecoq ${ }^{1}$, Cédric Orelle $^{1}$, Vincent Chaptal ${ }^{1}$, Pierre Falson ${ }^{1}$, Jean- \\ Michel Jault ${ }^{1}$, Beat H. Meier ${ }^{2 *}$, and Anja Böckmann ${ }^{1 *}$ \\ ${ }^{1}$ Molecular Microbiology and Structural Biochemistry, Labex Ecofect, UMR 5086 CNRS-Université \\ de Lyon, IBCP, 7 passage du Vercors, 69367 Lyon, France \\ ${ }^{2}$ Physical Chemistry, ETH Zurich, Vladimir-Prelog-Weg 2, 8093 Zurich, Switzerland
}

\section{"Corresponding authors: a.bockmann@ibcp.fr, beme@ethz.ch}

\begin{abstract}
We here adapted the GRecon method used in electron microscopy studies for membrane protein reconstitution to the needs of solid-state NMR sample preparation. We followed in detail the reconstitution of the $\mathrm{ABC}$ transporter $\mathrm{BmrA}$ by dialysis as a reference, and established optimal reconstitution conditions using the combined sucrose/cyclodextrin/lipid gradient characterizing GRecon. We established conditions under which quantitative reconstitution of active protein at low lipid-to-protein ratios can be obtained, and also how to upscale these conditions in order to produce adequate amounts for NMR. NMR spectra recorded on a sample produced by GRecon showed a highly similar fingerprint as those recorded previously on samples reconstituted by dialysis. GRecon sample preparation presents a gain in time of nearly an order of magnitude for reconstitution, and shall represent a valuable alternative in solid-state NMR membrane protein sample preparation.
\end{abstract}




\section{Introduction}

Membrane proteins represent an important class of molecules in living organisms, and are key players in the communication between cells, the transport of different metabolites inside or outside cells and signal transduction. A genome-wide analysis indeed predicts that 20 to $30 \%$ of all open reading frame encode for membrane proteins ${ }^{1}$; they indeed represent the largest class of drug targets ${ }^{2,3}$. Paradoxically, despite their importance, they are significantly underrepresented in the protein databank (www.rcsb.org) with only $2 \%$ of the structures therein (with 2150 membrane proteins structures, including 680 unique structures; http://blanco.biomol.uci.edu/mpstruc/). While most structural studies of membrane proteins were carried out by x-ray crystallography, electron microscopy and NMR are increasingly attractive near-atomic and atomic-resolution approaches respectively to study membrane proteins in a lipid environment, and possibly near physiological temperatures for NMR. Due to the anisotropy of the lipid-inserted protein phase, the NMR methods are usually characterized as solid-state NMR. It should however be kept in mind that these phases are investigated near room temperature and behave dynamically, as in vivo, and are far from being a real solid.

For both solid-state NMR and cryo-EM, membrane reconstitution of detergent-solubilized proteins is a central step on which further data analysis relies crucially ${ }^{6}$. In addition, reconstitution of membrane proteins is often important to study their properties in a more physiological environment. For instance, the ATPase activity of the maltose ABC transporter is insensitive to maltose in detergent, whereas the activity regulated by maltose when the transporter is reconstituted ${ }^{7}$. A common approach consists in adding the protein (dissolved in detergent I) to liposomes destabilized/solubilized with the same or different detergent (detergent II) ${ }^{8}$. These destabilized/solubilized liposomes are prone to protein insertion if detergent $\mathrm{I}$ is removed using either dialysis, chromatography ${ }^{9}$, addition of non-polar polystyrene beads ${ }^{10}$ or cyclodextrin ${ }^{11}$. Identifying optimal conditions is often a lengthy process that aims at finding the best ratios of the involved reagents in order to remove the detergents. The goal is to maximize insertion of the protein into the lipid environment to form proteoliposomes and to minimize aggregation.

A novel approach, the GRecon method, developed a few years ago by Kühlbrandt and coworkers in the context of electron microscopy sample preparation ${ }^{12}$, allows for gentle and progressive encounter between the different reagents, while at the same time reducing the 
total experiment time by about an order of magnitude when compared to dialysis. GRecon consists in the use of ultracentrifugation of the detergent-solubilized membrane protein on a combined sucrose, lipid (destabilized with detergent II) and cyclodextrin (chosen to primarily absorb detergent I) gradient for reconstitution. The protein during ultracentrifugation migrates down the gradient encountering an increasing amount of cyclodextrin. The cyclodextrin is chosen such as to absorb the detergent I molecules stabilizing the membrane protein with higher affinity than detergent II $^{11}$ needed to destabilize the lipids. Different cyclodextrins can be used for different detergents including N-Dodecyl-ß-D-maltoside (DDM), HECAMEG, $\mathrm{C}_{12} \mathrm{E}_{10}$ and Nonylglucose ${ }^{11}$. Remaining detergent II is mainly removed by dilution of the proteoliposomes after reconstitution. The major advantage of this method is the progressive increase or decrease in reactants, making it particularly attractive for the lipid reconstitution of large and/or fragile membrane proteins ${ }^{12}$.

Inspired by this work, we examined here the possibility to adapt this method to solid-state NMR membrane protein sample preparation where considerably larger protein amounts are needed, and close-to-quantitative recovery is a major issue. Also, typically smaller LPR (lipid-to-protein ratios) are preferred in NMR for sensitivity reasons. We here compared GRecon and reconstitution by dialysis of BmrA, a multidrug ABC transporter from Bacillus subtilis $^{13}$ that we used as a model here, as efficient reconstitution of this protein can be easily followed by its ATPase activity. ABC transporters can translocate a variety of molecules by coupling ATP hydrolysis with drug efflux. They are found in all forms of life, and in humans they are typically involved in drug resistance. We focus here on the ABC transporter BmrA from B. subtilis as a model, which is a homologue of the human P-gp identified to be involved in drug resistance in cancer. We show how GRecon can be up scaled for solid-state NMR needs, and that it results in a reduction of sample preparation time of about an order of magnitude when compared to the more classical dialysis method. We also evaluate the activity and superstructures of the resulting proteoliposomes, and demonstrate that NMR spectra recorded on GRecon samples yield very similar high-quality spectra to those observed after dialysis.

\section{Material and methods}

Production, purification and reconstitution of BmrA in B. subtilis lipids

Production, purification, and reconstitution of BmrA were done as previously described ${ }^{14}$. Briefly, uniformly $\left[{ }^{13} \mathrm{C},{ }^{15} \mathrm{~N}\right]$ labeled BmrA was produced in M9-medium ${ }^{15}$ with ${ }^{13} \mathrm{C}$-glucose 
( $2 \mathrm{~g} / \mathrm{L})$ and ${ }^{15} \mathrm{~N}$-ammonium chloride $(2 \mathrm{~g} / \mathrm{L})$ as sole sources of carbon and nitrogen. Two precultures were performed before the main culture. The first one was done in $50 \mathrm{~mL}$ M9medium, incubated at $37^{\circ} \mathrm{C}$ until an $\mathrm{OD}_{600 \mathrm{~nm}}$ of 1.5 . Then the second pre-culture, $150 \mathrm{~mL}$ of M9-medium, was inoculated with the first pre-culture (starting $\mathrm{OD}_{600 \mathrm{~nm}}$ of 0.2) and incubated over night at $25{ }^{\circ} \mathrm{C}$ until an $\mathrm{OD}_{600 \mathrm{~nm}}$ of 2.5 . Finally, the $150 \mathrm{~mL}$ from the last pre-culture were used to inoculate $850 \mathrm{~mL} \mathrm{M9-medium} \mathrm{of} \mathrm{the} \mathrm{main} \mathrm{culture.} \mathrm{The} \mathrm{latter} \mathrm{was} \mathrm{incubated} \mathrm{at} 25{ }^{\circ} \mathrm{C}$ and the expression was induced with $0.7 \mathrm{mM}$ IPTG at an $\mathrm{OD}_{600 \mathrm{~nm}}$ between $0.6-0.7$. The cells were harvested 6 hours after induction by centrifugation at 6’000 x $g$. The cells were suspended in buffer (50 mM Tris-HCl pH 8.0, $5 \mathrm{mM} \mathrm{MgCl}_{2}, 1 \mathrm{mM}$ DTT with benzonase and EDTA-free protease inhibitor cocktail) and disrupted by high fluid pressure using a Microfluidizer $^{\circledR}$. The solution was centrifuged at $15^{\prime} 000 \mathrm{x} g$ during one hour and the obtained supernatant was again centrifuged at 200'000 x $g$ during one hour. The sedimented membranes were suspended and collected in $50 \mathrm{mM}$ Tris- $\mathrm{HCl} \mathrm{pH}$ 8.0, $1 \mathrm{mM}$ EDTA, $300 \mathrm{mM}$ sucrose. For the purification of the protein, the membranes were diluted at $2 \mathrm{mg} / \mathrm{mL}$ and incubated during one hour with $1 \% \operatorname{DDM}(\mathrm{m} / \mathrm{v})$. The insoluble material was sedimented by centrifugation at $100^{\prime} 000 \times \mathrm{g}$ for one hour and discarded. The soluble material was loaded on to a Ni-NTA agarose column equilibrated with equilibration buffer $(50 \mathrm{mM}$ Tris- $\mathrm{HCl} \mathrm{pH} 8.0$, $100 \mathrm{mM} \mathrm{NaCl}, 15 \%$ glycerol, $10 \mathrm{mM}$ imidazole and 0.2\% DDM). The column was washed using equilibration buffer with successively $0.5 \mathrm{M} \mathrm{NaCl}, 30 \mathrm{mM}$ imidazole, $40 \mathrm{mM}$ imidazole and $250 \mathrm{mM}$ imidazole was used for the elution of the protein. The imidazole was removed using PD10 desalting columns equilibrated with $50 \mathrm{mM}$ Tris- $\mathrm{HCl} \mathrm{pH} 8.0,100 \mathrm{mM} \mathrm{NaCl}$, $10 \%$ glycerol and $0.2 \%$ DDM. For reconstitution by dialysis, the protein was diluted 4 times with $50 \mathrm{mM}$ Tris- $\mathrm{HCl} \mathrm{pH} 8.0,100 \mathrm{mM} \mathrm{NaCl}, 10 \%$ glycerol, mixed and incubated one hour with a homemade preparation of $B$. subtilis lipids solubilized in Triton X-100 ${ }^{14}$. The quantity of lipids mixed follows a determined lipid-to-protein ratio (LPR) of 0.1-20 (m:m). The DDM and Triton X-100 were removed by dialysis with Bio-beads (in the dialysis solution) during 9 days. The quantity of Bio-beads used was three times the theoretical amount required to absorb the DDM and Triton X-100 present in the solution. The theoretical amount of the adsorption capacities from Bio-beads was previously described and correspond to $105 \mathrm{mg}$ DDM per $1 \mathrm{~g} \mathrm{Bio-beads}^{8}$ and $70 \mathrm{mg}$ Triton X-100 per $1 \mathrm{~g}$ Bio-beads (Bio-Rad, user manual).

\section{Gradient Reconstitution and upscale thereof}

The $30-60 \%$ sucrose $(\mathrm{m} / \mathrm{v})$ gradients used for the small-scale reactions were performed in SW60 ultracentrifuge tubes (Seton - Open-top centrifuge tubes polyclear ${ }^{\mathrm{TM}} ; 11$ x $60 \mathrm{~mm}$, 
volume $4 \mathrm{~mL}$ ). $1.9 \mathrm{~mL}$ of $30 \%$ sucrose in $50 \mathrm{mM}$ Tris- $\mathrm{HCl} \mathrm{pH} 8,100 \mathrm{mM} \mathrm{NaCl}$ were deposited on $1.9 \mathrm{~mL}$ of $60 \%$ sucrose in $50 \mathrm{mM}$ Tris- $\mathrm{HCl} \mathrm{pH} \mathrm{8,} 100 \mathrm{mM} \mathrm{NaCl}, 0-3 \%$ (m/v) $\alpha$-cyclodextrins, and $0.08 \mathrm{mg} / \mathrm{mL}$ B. subtilis lipids destabilized with Triton ${ }^{\mathrm{TM}} \mathrm{X}-100$ (Sigma) ratio 1:1 $(\mathrm{m} / \mathrm{m})$. The continuous gradient was obtained using a Gradient Master $^{\mathrm{TM}}$ (BioComp Instuments) with the following parameters: angle $86^{\circ}, 18 \mathrm{rpm}$, during $65 \mathrm{sec} .300 \mu \mathrm{g}$ of protein $(1 \mathrm{mg} / \mathrm{mL})$ corresponding to $4.5 \mathrm{nmol}$ of BmrA monomer were loaded on the top of the gradient and the gradient was ultracentrifuged at $175^{\prime} 000 \times \mathrm{g}$ during $15 \mathrm{~h}$. Each gradient was photographed, and 19 layers of $200 \mu \mathrm{L}$ were collected. They were analyzed by SDSPAGE (10\% acrylamide) and a BCA assay (Pierce ${ }^{\mathrm{TM}}$ BCA Assay Kit, Thermo Scientific), as well as an ATPase assay (see below) for each layer containing protein sample. The $30-60 \%$ sucrose gradients were operated in 12 SW32 ultracentrifuge tubes (Seton - Open-top centrifuge tubes polyclear $^{\mathrm{TM}} ; 25 \times 89 \mathrm{~mm}$, volume $38.5 \mathrm{~mL}$ ). $17 \mathrm{~mL}$ of $30 \%$ sucrose in 50 $\mathrm{mM}$ Tris- $\mathrm{HCl} \mathrm{pH} 8,100 \mathrm{mM} \mathrm{NaCl}$ were deposited on $17 \mathrm{~mL}$ of $60 \%$ sucrose in $50 \mathrm{mM}$ Tris$\mathrm{HCl} \mathrm{pH} \mathrm{8,} 100 \mathrm{mM} \mathrm{NaCl}, 1 \%(\mathrm{~m} / \mathrm{v}) \alpha$-cyclodextrins, and $0.09 \mathrm{mg} / \mathrm{mL}$ B. subtilis lipids destabilized with Triton ${ }^{\mathrm{TM}} \mathrm{X}-100$ (Sigma) ratio 1:1 (m/m). The continuous gradient was generated using a Gradient Master ${ }^{\mathrm{TM}}$ (BioComp Instuments) with the following parameters, step 1: angle $50^{\circ}, 25 \mathrm{rpm}$, during $6 \mathrm{~min}$, step 2: angle $82^{\circ}, 15 \mathrm{rpm}$, during $40 \mathrm{sec} .3 \mathrm{mg}$ of protein $(1 \mathrm{mg} / \mathrm{mL})$ corresponding to $45 \mathrm{nmol}$ protein monomer were loaded on the top of the gradient and the gradient was ultracentrifuged at 175'000 x $g$ during $15 \mathrm{~h}$. The gradient was photographed and 23 layers of $1.6 \mathrm{~mL}$ were collected and analyzed by SDS-PAGE (10\% acrylamide). The fractions containing protein were pooled, the proteoliposomes were harvested by sedimentation at 100'000 x $g$ during $1 \mathrm{~h}$ and washed 8 times in order to remove the excess of sucrose and $\alpha$-cyclodextrins. The proteoliposomes were transferred into a 3.2 $\mathrm{mm}$ NMR rotor by centrifugation at $100^{\prime} 000 \mathrm{x} g$ with a custom-made filling tool ${ }^{16}$.

\section{Quantification of DDM by Mass Spectroscopy}

DDM was quantified as previously described ${ }^{17}$. Briefly, four different ratios ${ }^{1} \mathrm{H}-\mathrm{DDM}:{ }^{2} \mathrm{H}-$ DDM were measured to establish a standard curve: 1:5, 1:2, 1:1 and 3:1. The concentration of ${ }^{2} \mathrm{H}-\mathrm{DDM}$ was constant and equal to $0.025 \%(\mathrm{~m} / \mathrm{v})$. The different ratios were determined experimentally by MALDI-TOF using the peak intensities from ${ }^{1} \mathrm{H}-\mathrm{DDM}$ and ${ }^{2} \mathrm{H}-\mathrm{DDM}$. To determine the ${ }^{1} \mathrm{H}-\mathrm{DDM}:{ }^{2} \mathrm{H}-\mathrm{DDM}$ ratios during the reconstitution, aliquots were collected directly from the dialysis bag at the following times: $0 \mathrm{~h}, 0.5 \mathrm{~h}, 1 \mathrm{~h}, 2 \mathrm{~h}, 4 \mathrm{~h}, 8 \mathrm{~h}, 1 \mathrm{~d}, 2 \mathrm{~d}, 3 \mathrm{~d}$, $4 \mathrm{~d}, 5 \mathrm{~d}, 6 \mathrm{~d}, 7 \mathrm{~d}, 8 \mathrm{~d}$ and $9 \mathrm{~d}$. A dilution by 2.5 times for the samples $0 \mathrm{~h}$ to $2 \mathrm{~d}$ was done and each aliquot were mixed with $0.025 \%(\mathrm{~m} / \mathrm{v}){ }^{2} \mathrm{H}-\mathrm{DDM}$. The different ${ }^{1} \mathrm{H}-\mathrm{DDM}:{ }^{2} \mathrm{H}-\mathrm{DDM}$ 
ratios were determined by MALDI-TOF and reported to the standard curve in order to determine the concentration of ${ }^{1} \mathrm{H}$-DDM. In order to avoid the pipetting error and to increase the accuracy of the method, all volumes used were weighted with a precision scale. All experiments were done in triplicate. Each sample was mixed in 10:1 ratio with matrix $(10 \mathrm{~g} / \mathrm{L}$ $(\mathrm{m} / \mathrm{v})$ DHB (2,5-dihydroxybenzoic acid) in water and $1 \mathrm{~g} / \mathrm{L}(\mathrm{m} / \mathrm{v}) \mathrm{NaI}$ acetone), $1 \mu \mathrm{L}$ of mixture was deposited on the MALDI-target and air-dried. Mass spectrometry experiments were performed with a Voyager-DE Pro MALDI-TOF (AB Sciex, Framingham, MA) Mass Spectrometer with a nitrogen UV laser ( $\lambda=337 \mathrm{~nm}, 3 \mathrm{~ns}$ pulse). The instrument was operated in reflectron-positive ion mode (mass accuracy: 0.008\%) with an accelerating potential of 5 $\mathrm{kV}$.

\section{ATPase activity assay}

To determine the ATPase activity, two assays were used: an ATP/NADH coupled ATPase activity assay, and a colorimetric ATPase activity assay. The colorimetric assay allowed determining the concentration of inorganic phosphate without dilution engendered by the ATP-regeneration buffer. This assay was useful to determine the detergent effect on the activity when the detergent concentration was unknown.

Colorimetric ATPase activity assay: We followed the method described by Doerrler and Raetz $^{18}$. Briefly, $250 \mu \mathrm{L}$ of reconstituted BmrA $(0.2 \mathrm{mg} / \mathrm{mL})$ in $50 \mathrm{mM}$ Tris- $\mathrm{HCl}, 200 \mathrm{mM}$ $\mathrm{NaCl}, 5 \%$ glycerol was incubated $5 \mathrm{~min}$ at $37{ }^{\circ} \mathrm{C}$. The ATPase reaction was started by the addition of $5 \mu \mathrm{L}$ ATP- $\mathrm{Mg}^{2+}$ from a stock solution of $500 \mathrm{mM}$. $25 \mu \mathrm{L}$ of the reaction medium were pipetted and mixed with $25 \mu \mathrm{L} 12 \%$ SDS. $25 \mu \mathrm{L}$ of $6 \%$ ascorbic acid in $1 \mathrm{M} \mathrm{HCl}$ and $2 \%$ ammonium molybdate were added, and the colorimetric reaction was incubated $5 \mathrm{~min}$ at room temperature. $50 \mu \mathrm{L}$ of $1 \mathrm{M} \mathrm{HCl}$ were then added in order to slow down drastically the colorimetric reaction. The absorbance at $850 \mathrm{~nm}$ was measured and the quantity of orthophosphate was determined using a $\mathrm{Na}_{2} \mathrm{HPO}_{4}$ standard $(0-50 \mu \mathrm{mol})$.

NADH coupled ATPase activity assay: The ATPase activity of BmrA was quantified using a coupled enzyme assay. ATP is regenerated by a pyruvate kinase from phosphoenolpyruvate and ADP. The regeneration system was coupled with a second system using lactate dehydrogenase and NADH. For ATP one molecule of NADH was transformed into $\mathrm{NAD}^{+}$. The absorbance of NADH was followed at $340 \mathrm{~nm}$ during the reaction (spectrophotometer SAFAS FLX-Xenius ${ }^{\circledR}$ ). The assay was done at $37{ }^{\circ} \mathrm{C}$ in a 96 well microplate (UV-star ${ }^{\circledR}$ Microplate, 96 well - Greiner Bio-one) pre-incubated at $37^{\circ} \mathrm{C}$. In each microplate well, 0.1 
$\mu \mathrm{g}$ of reconstituted BmrA (LPR 0-20) was deposited or $0.1 \mu \mathrm{g}$ of reconstituted BmrA (LPR 0.5 ) was mixed with an increasing concentration of N-Dodecyl-ß-D-maltoside (DDM), 0-2 \% $(\mathrm{m} / \mathrm{v})$ in ATPase buffer for both cases $(50 \mathrm{mM}$ HEPES-KOH $\mathrm{pH} \quad 8,4 \mathrm{mM}$ phosphoenolpyruvate, $60 \mu \mathrm{g} / \mathrm{mL}$ pyruvate kinase, $32 \mu \mathrm{g} / \mathrm{mL}$ lactate dehydrogenase, $10 \mathrm{mM}$ $\mathrm{MgCl}_{2}, 0.6 \mathrm{mM}$ NADH) qsq $200 \mu \mathrm{L}$. The reaction was started by the addition of $5 \mathrm{mM}$ ATP and was followed during $20 \mathrm{~min}$. The ATP activity was determined using the NADH extinction coefficient $(6220 \mathrm{~L} / \mathrm{mol} / \mathrm{cm})$, the radius of a well $(3.3 \mathrm{~mm})$ and the sample volume $(200 \mu \mathrm{L})$ allow us to determine a path length of $0.585 \mathrm{~cm}$.

\section{Solid-state NMR experiments}

NMR spectra were acquired on a Bruker Avance spectrometer operating at $850 \mathrm{MHz}{ }^{1} \mathrm{H}$ frequency using a $3.2 \mathrm{~mm}$ triple-resonance E-free probe. The details of NMR experiments are given in the Table S1. The sample temperature was set to $278 \mathrm{~K}$ using the water resonance frequency. The $2 \mathrm{D}$ spectra were processed using TOPSIN 3.5 with a shifted $\cos ^{2}(\mathrm{SSB}=3)$ function and analyzed using CcpNMR software ${ }^{19}$.

\section{Results and Discussion}

\section{Reconstitution of BmrA in lipids by dialysis}

BmrA has been shown to be stable (i.e. protected against degradation) and active (i.e. ATPase competent) when reconstituted in lipids extracted from B. subtilis ${ }^{14}$. Also, NMR spectra do not reveal differences even after three years. We first implemented this previously described approach, which includes the addition of Bio-beads to the dialysis buffer to remove the DDM (detergent I) and Triton X-100 (detergent II, 10:1 ratio to lipids) ${ }^{14}$. For BmrA, a lipid-protein ratio of $0.5 \mathrm{~m} / \mathrm{m}$ (or $35 \mathrm{~mol} / \mathrm{mol}$ ) allows to obtain samples with high stability over a time period of months ${ }^{14}$. Lower LPRs could in principle be used, but we did not test them yet to prepare an NMR sample. LPRs lower than 0.1 did however not yield the typical tubular superstructures anymore (see below). When such low LPRs are used, very slow detergent removal is beneficial in order to avoid aggregation. We used dialysis during 9 days, with Biobeads present in the dialysis buffer only. For comparison, direct addition of Bio-beads to prepare an LPR $=20$ sample needs only $3 \mathrm{~h}$ for full detergent removal ${ }^{20}$, but leads to protein aggregation at $\mathrm{LPR}=0.5$. 
In order to establish the time scale of the reconstitution, we followed the ATPase activity of BmrA and determined remaining detergent I concentrations by mass spectrometry $(\mathrm{MS})^{17}$ (Figure 1A). The calibration curve is presented in the supplementary data (Figure S1). After two days of incubation, half of the initial quantity of the detergent I was depleted and its concentration reached a minimum after five to six days as determined by mass spectrometry (Figure S2). A second addition of Bio-beads, after 6 days, and three more days of incubation, did not remove additional detergent. In this reaction, detergent I was five times more concentrated than detergent II, for which no signal was detected already after four days of dialysis. In parallel, the ATPase activity of BmrA was monitored (Figure 1A). It has been shown that reconstituted proteins may be substantially more active than detergent-stabilized ones $^{21,22}$. Experimentally, the depletion of DDM was in the first place accompanied by a decrease in ATPase activity (after one to two days of incubation), and only increases when the DDM concentration falls below its CMC $(0.009 \%$ (Anatrace)). This phenomenon was also described for a progressive delipidation of sarcoplasmic reticulum $\mathrm{Ca}^{2+}-$ ATPase by DDM and $\mathrm{C}_{12} \mathrm{E}_{8}$ and is so far unexplained ${ }^{23}$. No transport activity was measured as a function of LPR, as inverted membrane vesicles are needed for this ${ }^{13}$.

Reconstitution was also followed by EM (Figure 1B and S3). BmrA is known to change the structure of liposomes (B. subtilis lipids or EPC/EPA) to form ring-shaped protein/lipid assemblies that combine at low detergent concentrations and low LPR into annular or tubular superstructures $^{14,22,24}$. The liposome-protein mixture before the initiation of the detergent depletion by dialysis is shown in Figure $1 \mathrm{~B}$ at $0 \mathrm{~h}$. After two days of incubation (2d), a mixture of rings and tubular structures appears, the latter of around $200 \mathrm{~nm}$ length with a diameter of $20 \mathrm{~nm}$. The length of the tubular structures increases during the detergent depletion and can reach more than $1 \mu \mathrm{m}$ after six days of incubation. At the end of the process, the structures form a conglomerate of tubular particles with different sizes (9d). 
A

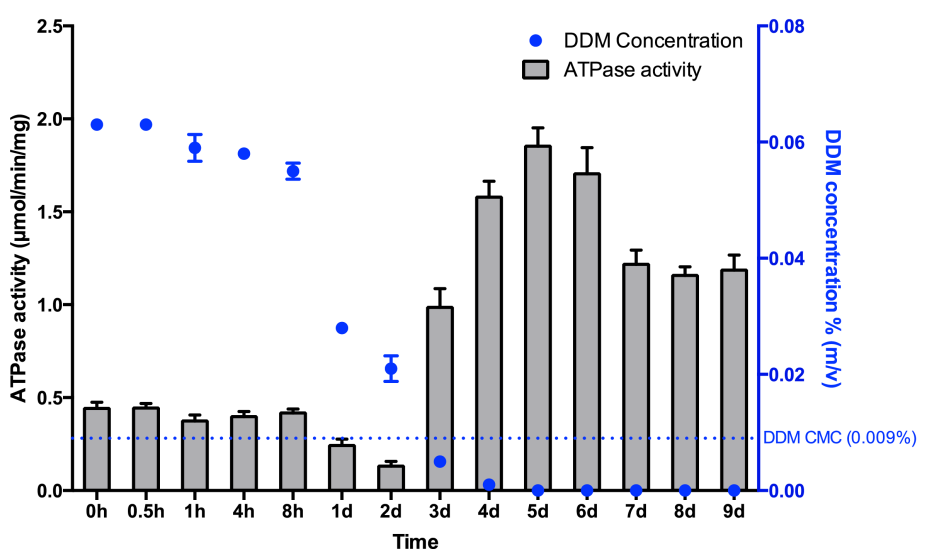

2d

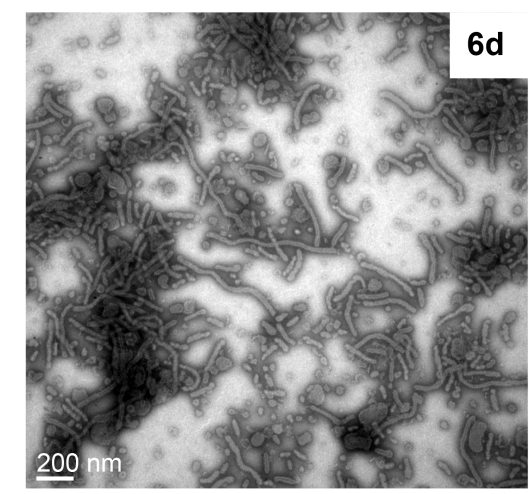

B
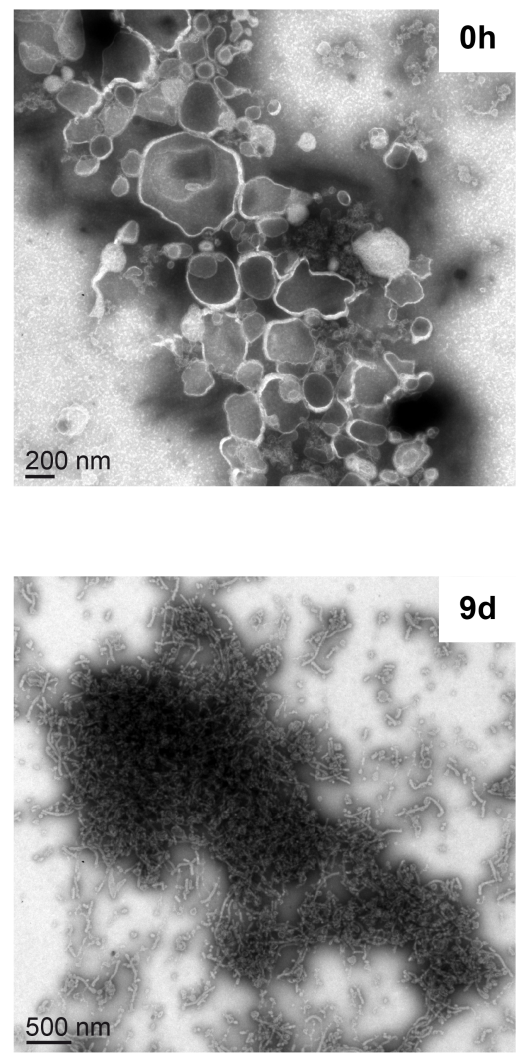

Figure 1: (A) ATPase activity of BmrA (grey histogram) and DDM concentration (blue dots) during lipid reconstitution. ATPase activities were monitored by the quantification of inorganic phosphate resulting from ATP hydrolysis by BmrA. DDM was quantified by MALDI-TOF mass spectrometry using ${ }^{2} \mathrm{H}-\mathrm{DDM}$ as an internal standard. In parallel, each sample was observed by EM (B). The EM pictures at times equals to $0 \mathrm{~h}, 2 \mathrm{~d}, 6 \mathrm{~d}, 9 \mathrm{~d}$ are presented, and all data points are shown in Figure S3.

\section{GRecon}

When using GRecon for NMR sample preparation, it is important that the reconstitution is as quantitative as possible, in order not to lose isotope-labeled protein, and to obtain the desired protein-to-lipid ratio in the rotor. In this context, the following parameters have to be determined:

(i) The sucrose gradient to be used as a function of the chosen lipid/protein ratio.

(ii) The amount of cyclodextrin needed per mole unit of protein for removing the detergent by a precipitation test. 
(iii) The optimum amount of cyclodextrin in the gradient.

\section{(i) LPR and sucrose gradient}

The amount of lipids $n_{l}$ to be added to the initial bottom layer of the gradient depends on the desired LPR, $X$, and the amount of protein, $n_{p}$. The amount of lipids is calculated as = where $M_{p}$ and $M_{l}$ denote the molecular weights of protein and lipids, respectively. After deciding on the LPR, the sucrose gradient has to be adjusted so that the protein ultimately ends up in the bottom third of the gradient once it is fully reconstituted. If the sucrose gradient is not optimal, the protein may stay too high in the gradient and not encounter enough cyclodextrin to complete its reconstitution. The lower the LPR, the further the protein will in general migrate in the gradient ${ }^{14}$. Even if the protein does not migrate all the way to the bottom of the centrifuge tube, it will encounter all lipids added as they tend to move up during centrifugation. Lipids from B. subtilis were mixed with Triton-X100 at a ratio of $1(\mathrm{~m} / \mathrm{m})$.

In the original work of Kühlbrandt and coworkers ${ }^{12}$, LPRs of 3 to 4 were used in protein reconstitution for electron microscopy. For solid-state NMR sample preparation, we reduced the LPR in the BmrA sample to LPR 0.5, for signal-to-noise reasons, which has been shown to still yield high-quality NMR spectra for BmrA ${ }^{14}$. Under this condition, BmrA reconstituted by dialysis migrates to $47 \%$ sucrose (Figure $2 \mathbf{A}$ ).

In addition, the gradient should be chosen so that the protein solubilized in detergent stays towards the top of the gradient. BmrA in DDM migrates to $32 \%$ sucrose (Figure 2A) and DDM did not enter the gradient (Figure S4). (The migration behavior of detergent in sucrose gradients has also been described by Hauer and co-workers who used this approach to remove excess of detergent in order to increase the quality of cryo-microscopy data ${ }^{25}$.) The gradient was thus chosen as 30-60\%, and was produced using a BioComp gradient maker device. The gradient was approximately linear as verified by coomassie blue staining (Figure S5) ${ }^{26}$.

\section{(ii) Precipitation test}

In this second step, a precipitation test establishes how much cyclodextrin is needed to strip the detergent off the protein. An experimental procedure is then used in step (iii) to establish where this amount should be present in the gradient in order to allow for quantitative reconstitution. 
While other cyclodextrins absorb detergent as well, we here used $\alpha$-cyclodextrin, as it absorbs easily DDM (detergent I) and shows lower affinity for triton X-100 (detergent II) ${ }^{11}$. For the precipitation test, dissolved protein (in detergent I) was mixed with increasing amounts of $\alpha$ cyclodextrin $^{12}$ until complete precipitation of the protein was observed. This total amount of $\alpha$-cyclodextrin (in mole) is called $n_{t}$. With known buffer detergent and protein amounts, the precipitation test allows an estimation of the quantity (in mole) of detergent bound to the protein $\left(n_{d}\right)$ under the assumption that 1 cyclodextrin molecule binds one detergent molecule ${ }^{11}$. The amount (in mole) of protein is denoted by $n_{p}$, and we assume that one molecule represents one monomer.

Using the conditions under which BmrA was purified, i.e. $n_{p}=0.5 \mathrm{nmol}$ of protein in $27 \mu \mathrm{L}$ of BmrA at $18.5 \mu \mathrm{M}$ in a buffer containing $n_{b}=105 \mathrm{nmol} \mathrm{DDM}(0.2 \% ; 3.9 \mathrm{mM})$, precipitation of the protein was complete when exceeding $n_{\mathrm{t}}=203 \mathrm{nmol}$ cyclodextrin. (Figure 2B). This corresponds to a molar ratio of $n_{\mathrm{t}} / n_{\mathrm{p}}=406: 1 \alpha$-cyclodextrin:BmrA, and $n_{t} / n_{b}=203: 105 \alpha$ cyclodextrin:DDM(in the buffer). A roughly twofold excess of $\alpha$-cyclodextrin with respect to the DDM in the buffer seems thus necessary to remove the DDM in the sample. This is due to the fact that DDM is not only present in the buffer, but is also bound to the protein. The excess of roughly $200 \mathrm{nmol}$ of $\alpha$-cyclodextrin needed thus absorbs the DDM molecules which are bound to one nmol of BmrA, corresponding to $n_{d}$. This coincides well with previous estimations of $200 \pm 80 \mathrm{nmol}^{27}$ and $210 \pm 20 \mathrm{nmol}^{17}$ of DDM per nmol of BmrA. We will use in the following the approximate values of 200 detergent molecules bound to $1 \mathrm{nmol}$ of BmrA $\left(n_{d} / n_{p}=200: 1\right)$

(iii) The cyclodextrin gradient

In this third step, we determined where the total cyclodextrin amount necessary to strip the detergent off the protein should be present in the gradient. The protein should, on its way from the top (detergent solubilized, $32 \%$ sucrose) to the final position in the tube (membrane reconstituted, $47 \%$ sucrose), encounter the integral amount of cyclodextrin needed to fully absorb the protein-bound detergent (Figure 2C). In order to determine where the protein needs to make this encounter for quantitative reconstitution, BmrA is a valuable model since one can easily follow the efficient reconstitution of the protein with its ATPase activity. 


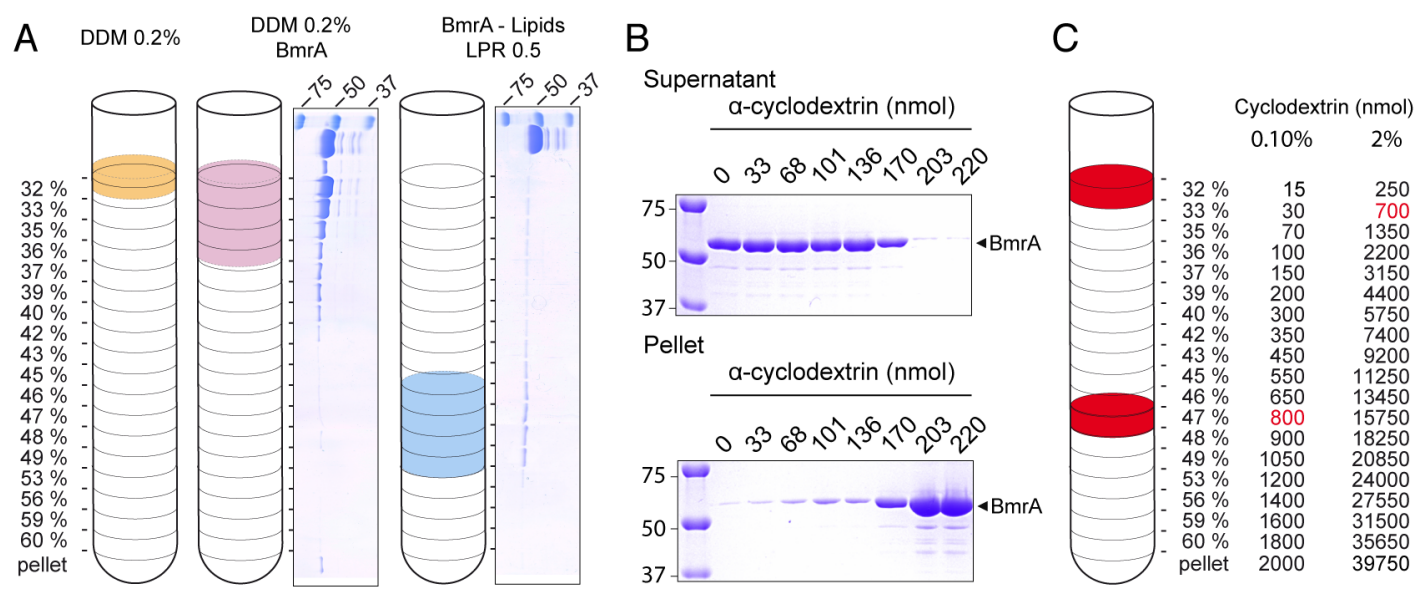

Figure 2. (A) Migration inside the sucrose gradient of DDM, BmrA in $0.2 \%$ DDM and BmrA in lipids LPR 0.5. The top line in the gels, after the marker, corresponds to the sample load before centrifugation. (B) Quantity of $\alpha$-cyclodextrin (nmol) needed to precipitate $0.5 \mathrm{nmol}$ of BmrA by depletion of DDM. The supernatant and the pellet were obtained after centrifugation of the precipitated samples at $20^{\prime} 000 \times \mathrm{g}$ during $30 \mathrm{~min}$. (C) Sketch of sucrose and $\alpha-$ cyclodextrin gradients corresponding to the two extreme cases of cyclodextrin concentrations $(0.1$ and $2 \%)$. The sucrose percentages along the tube are indicated in the left column, while the theoretical amounts of cyclodextrin along this gradient are indicated in the two right columns. The minimum quantity of $\alpha$-cyclodextrin required to remove the detergent of $300 \mu \mathrm{g}$ of BmrA and the corresponding layers in the gradient are highlighted in red. The expected needed amount of cyclodextrin should be located between these two extreme values, and they thus indicate the range of $\alpha$-cyclodextrin concentrations to be tested.

The $900 \mathrm{nmol}$ cyclodextrin needed to strip the detergent off the $4.5 \mathrm{nmol}(300 \mu \mathrm{g})$ of BmrA deposited on the gradient is indicated for 30-60\% sucrose gradients containing $0.25 \%$, $0.50 \%, 1 \%$ and $2 \%$ of $\alpha$-cyclodextrin in Figure S6. The resulting migration profiles for these conditions, plus a control without cyclodextrin, are displayed in Figure 3. After ultracentrifugation, each layer of each gradient was collected and analyzed by SDS-PAGE shown next to the tubes. The ATPase activities were monitored for the layers containing protein and are shown below the tubes.

Three different migration profiles of the protein in the gradients can be distinguished. Without cyclodextrin and with the lowest $\alpha$-cyclodextrin concentration $(0.25 \%)$, depletion of detergent seems not efficient, and only part of the protein reconstitutes into liposomes (the part that moves the furthest along the gradient). The corresponding fractions contain little protein but with a high ATPase activity, which, as will be shown below (Figure S7), is an indication that 
this fraction is reconstituted with a higher LPR, around 2. Interestingly, even when there is no $\alpha$-cyclodextrin, BmrA can be partially reconstituted into the lipids. This might be due to partial stripping of detergent by dilution. At the highest cyclodextrin concentration ( $2 \%)$, no band of lipids can be observed in the centrifugation tubes, and a protein-free pellet was formed. This might indicate that $\alpha$-cyclodextrin at high concentration does interact with the lipids in triton X-100 (detergent II), forming a precipitate. No reconstitution of the protein was observed, and very low ATPase activities are detected. In the intermediate range, with gradients of $0.5 \%$ and $1 \% \alpha$-cyclodextrin, the balance of the different concentrations seems appropriate and the ATPase activities of the collected fractions are comparable to those measured following reconstitution by dialysis, especially for the $1 \%$ gradient. The best choice of the gradient seems to be therefore $1 \% \alpha$-cyclodextrin, where all protein-containing fractions show active protein with a similar specific ATPase activity. One can note that this cyclodextrin concentration is the only one where the protein passes through the point in the gradient where the cumulated cyclodextrin quantity equals the quantity needed to strip off all detergent (red bars in Figure 3A, see also Figure S6). Even if it might be necessary to test several cyclodextrin concentrations when applying the method to other proteins, one might consider this to be a general requirement for successful reconstitution. 
A $0 \%$ a-cyclodextrin

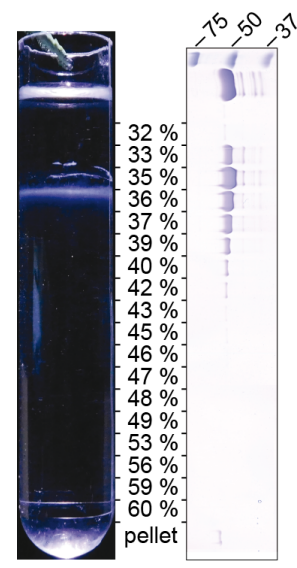

B

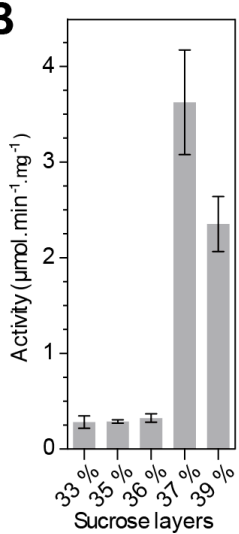

$0.25 \%$ a-cyclodextrin
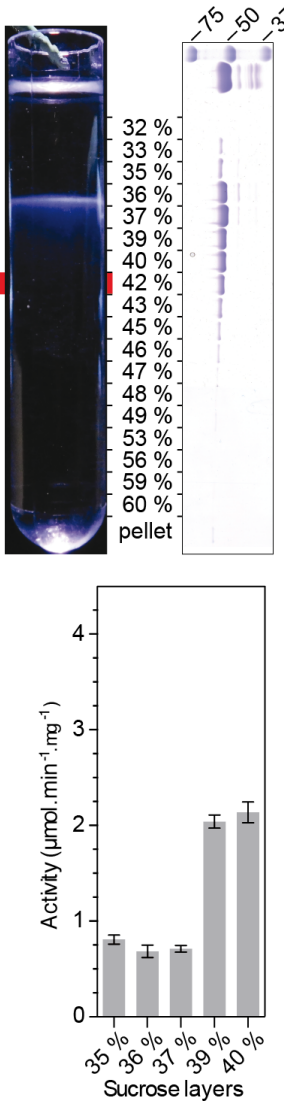

$0.5 \%$ a-cyclodextrin
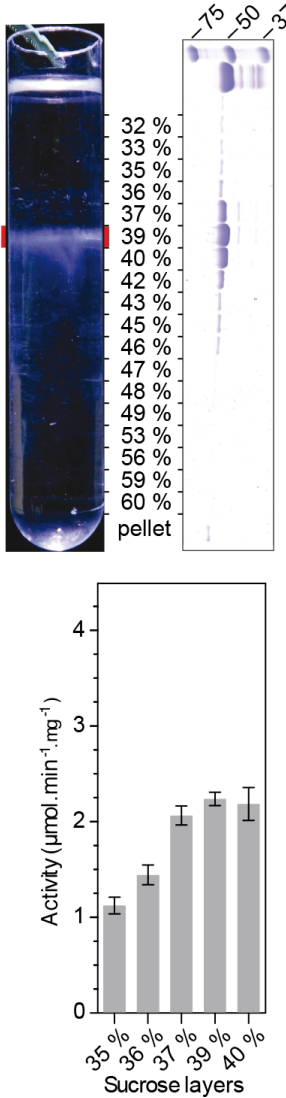

$1 \%$ a-cyclodextrin
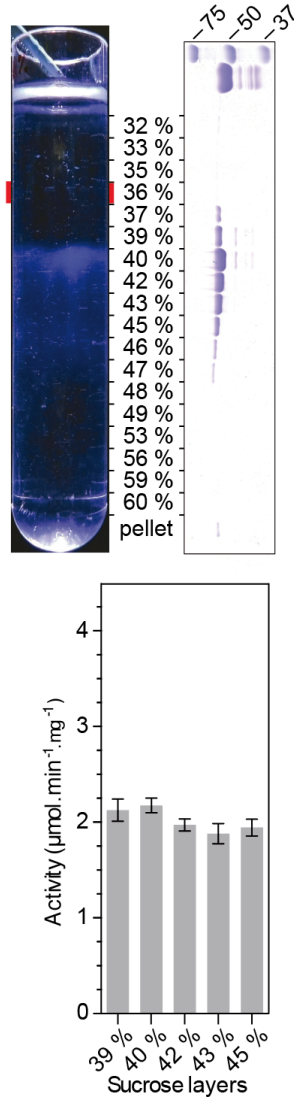

2\% a-cyclodextrin
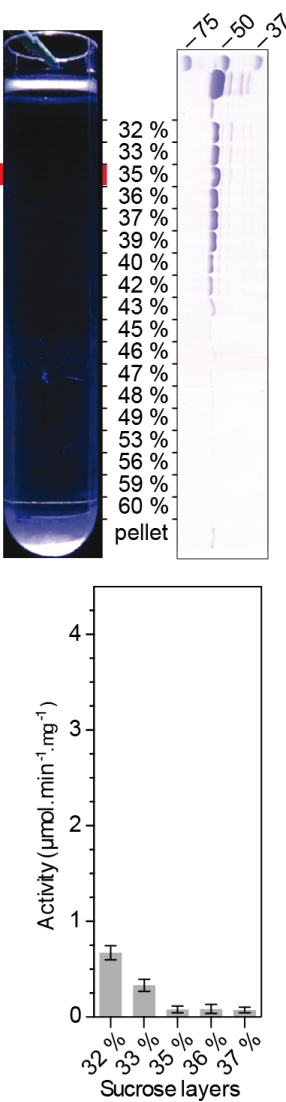

Figure 3. Determination of the best $\alpha$-cyclodextrin concentration using ATPase activity readout. Gradient reconstitution of BmrA in lipids (LPR 0.5) using various $\alpha$-cyclodextrin concentrations. The image of the gradient tube, the corresponding SDS-PAGE gels for each layer of the gradient (top line in the gels, after the marker, corresponds to the sample load before centrifugation) (A), and ATPase activity for the layer containing a sufficient quantity of protein (B) are shown for a $\alpha$-cyclodextrin concentrations of $0 \%, 0.25 \%, 0.5 \%, 1 \%$ and 2 $\%$. The approximate position in each gradient where the quantity of $\alpha$-cyclodextrin necessary to fully strip the detergent is highlighted in red.

The maximum rate (Vmax) of ATPase activity, as well the Hill number were compared between BmrA in detergent, BmrA reconstituted in B. subtilis lipids by dialysis and by GRecon. Vmax values were determined to 580, 1700 and $2100 \mathrm{nmol} \cdot \mathrm{min}^{-1} \cdot \mathrm{mg}^{-1}$ and Hill numbers to $2.18 \pm 0.12,1.18 \pm 0.04,1.17 \pm 0.06$ respectively (Figure 4A). The Vmax of BmrA reconstituted by dialysis is comparable to previously published data for BmrA reconstituted in B. subtilis lipid at LPR of $0.5\left[\mathrm{Vmax} \approx 1300 \mathrm{nmol} \cdot \mathrm{min}^{-1} \cdot \mathrm{mg}^{-1}\right]^{14}$. However, the activity of the protein reconstituted by GRecon seems higher than after dialysis reconstitution. One can also 
note that the Hill number for BmrA in lipids, whether reconstituted by GRecon or by dialysis, is nearly two times smaller when compared to DDM. This strongly supports the notion that dialysis and GRecon yield the same product, but detergent-solubilize protein differs significantly. This also underlines the importance to study BmrA in lipid membranes. As observed also by the migration to somewhat lower sucrose concentrations in GRecon when compared to reconstitution by dialysis (Figure 2A), this higher activity is probably due to a slight difference in LPR. Indeed, we noticed that with increasing LPR, the activity of the protein increases (Figure S7) and reaches levels previously reported with a LPR of $20^{13,20}$. Using a reference curve, we determine the LPR after GRecon to be 0.72 instead of 0.5 (Figure 4B). We also observed that there was no difference between reconstitution in $E$. coli lipids and B. subtilis lipids (Figure S7). Finally, the presence of residual DDM seems to be negligible in GRecon. Indeed, when plotting the ATPase activity as a function of DDM concentration, (Figure 4C), we observed an important decrease of the BmrA activity starting from a DDM concentration around 0.003 \% DDM. Moreover, no DDM was detected by mass spectrometry after GRecon (Figure S8).
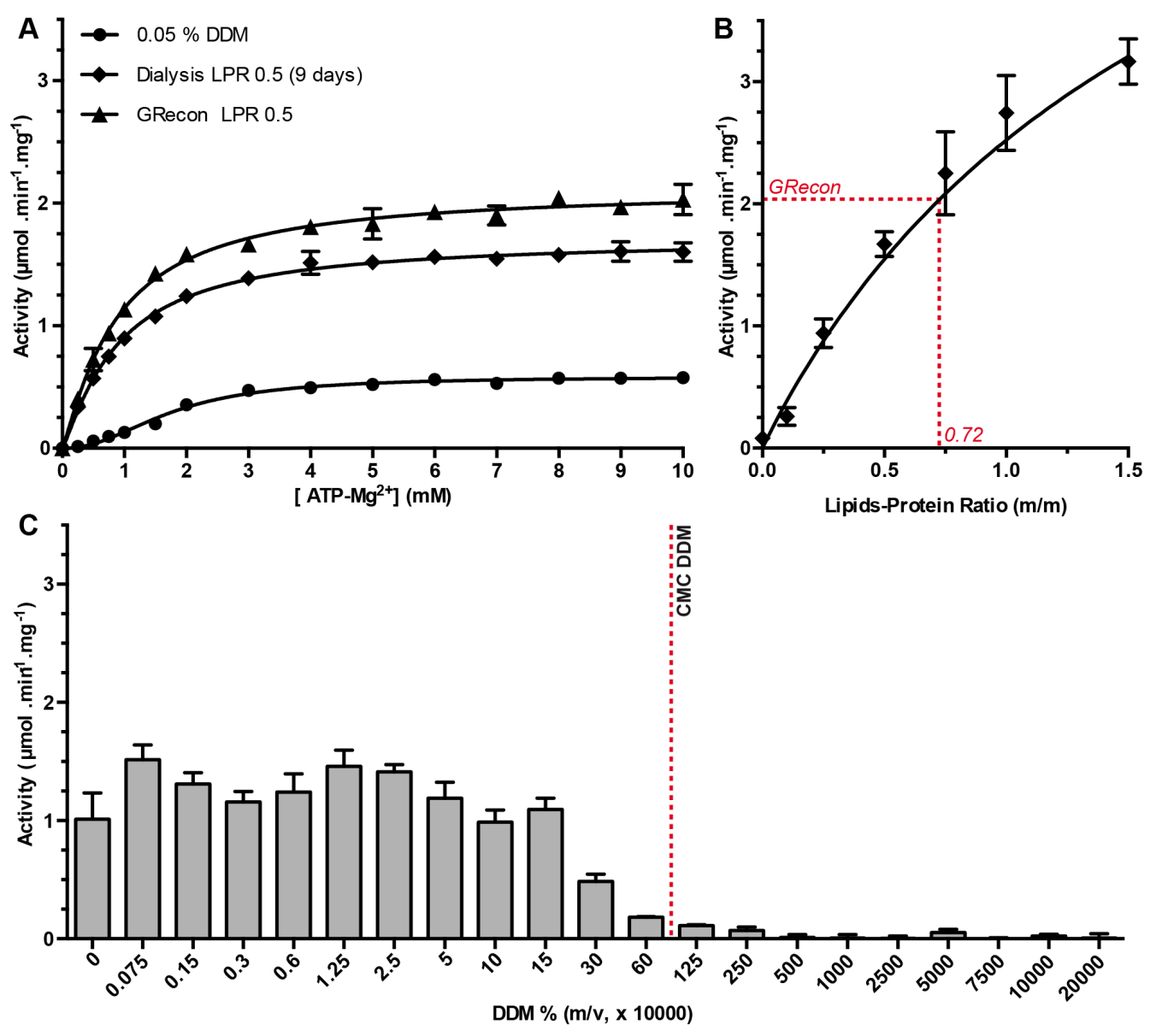
Figure 4. BmrA ATPase activities as a function of ATP- $\mathrm{Mg}^{2+}$ concentration and LPR. (A) ATPase activity of BmrA in $\operatorname{DDM}(\bullet)$ and reconstituted in lipids by dialysis $(\bullet)$ or GRecon $(\boldsymbol{\Delta})$, as a function of ATP- $\mathrm{Mg}^{2+}$. Data are shown as mean \pm standard deviation of quadruplicate values. The plots were fitted using GraphPad Prism and the values obtained for the different fits for $0.05 \%$ DDM, dialysis and GRecon respectively, were as follows: Vmax= $585 \pm 9,1712 \pm 18,2120 \pm 40 \mathrm{nmol} . \mathrm{min}^{-1} . \mathrm{mg}^{-1}$; Hill number $2.18 \pm 0.12,1.18 \pm 0.04,1.17 \pm 0.06$; $\mathrm{K}_{0.5} 1.75 \pm 0.12,0.9 \pm 0.3,0.9 \pm 0.2 \mathrm{mM}$. (B) ATPase activity as a function of LPR. The full graph showing LPRs up to 20, as well as a comparison to E. coli lipids, are presented in the supplementary information (Figure S7). The LPR of protein reconstituted by GRecon was estimated to 0.72 from the ATPase activity in presence of $10 \mathrm{mM} \mathrm{ATP.} \mathrm{(C)} \mathrm{Influence} \mathrm{of}$ increasing concentrations of DDM onto reconstituted BmrA at a LPR 0.5. Note that for convenient display, the values have been multiplied by 10000 .

\section{Upscaling for solid-state NMR sample preparation using GRecon method}

The condition obtained previously in SW60 tubes $(3.8 \mathrm{~mL})$ was upscaled to SW28 tubes (37 $\mathrm{mL}$ ). Indeed, the preparation using SW60 ultracentrifuge tubes only allows the reconstitution of $300 \mu \mathrm{g}(4.5 \mathrm{nmol})$ per tube. While this would be enough for proton-detected NMR under fast magic-angle spinning ${ }^{28}$, carbon-detected NMR requires larger amounts of sample and the method needed to be upscaled. Ten times more protein can be reconstituted using SW28 tubes where a sample of $3 \mathrm{mg}(45 \mathrm{nmol})$ of protein was laid on the top of the gradient (see also Figure S6). All other components need to be upscaled in the same ratio, yielding then the same concentration of the gradient components as in the small-scale trial. Centrifugation was performed at $175^{\prime} 000 \times \mathrm{g}$ during 15 hours. After the centrifugation step, an opaque band in layers of $36 \%$ to $42 \%(\mathrm{~m} / \mathrm{v})$ sucrose corresponding to the protein in lipids, and confirmed by SDS-PAGE, was observed (Figure 5A). 
A

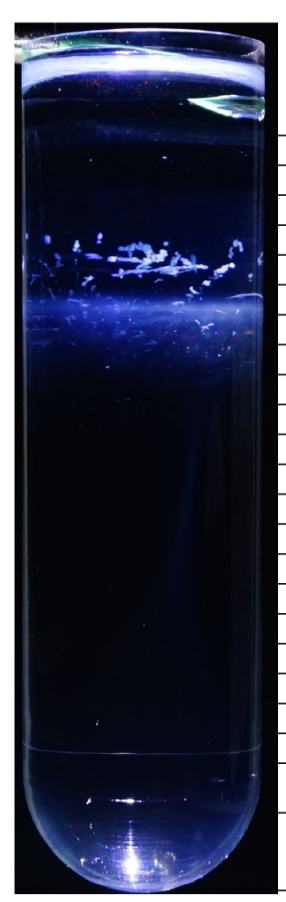

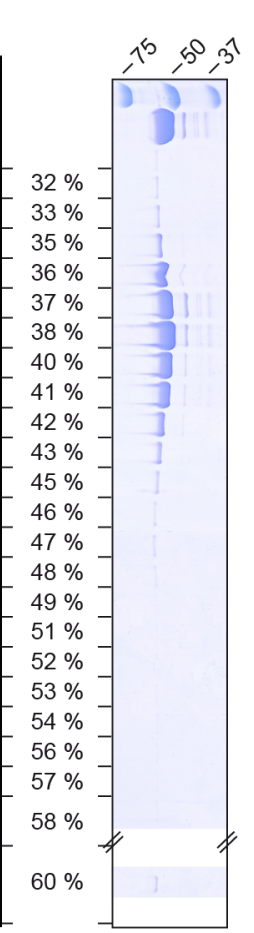

B
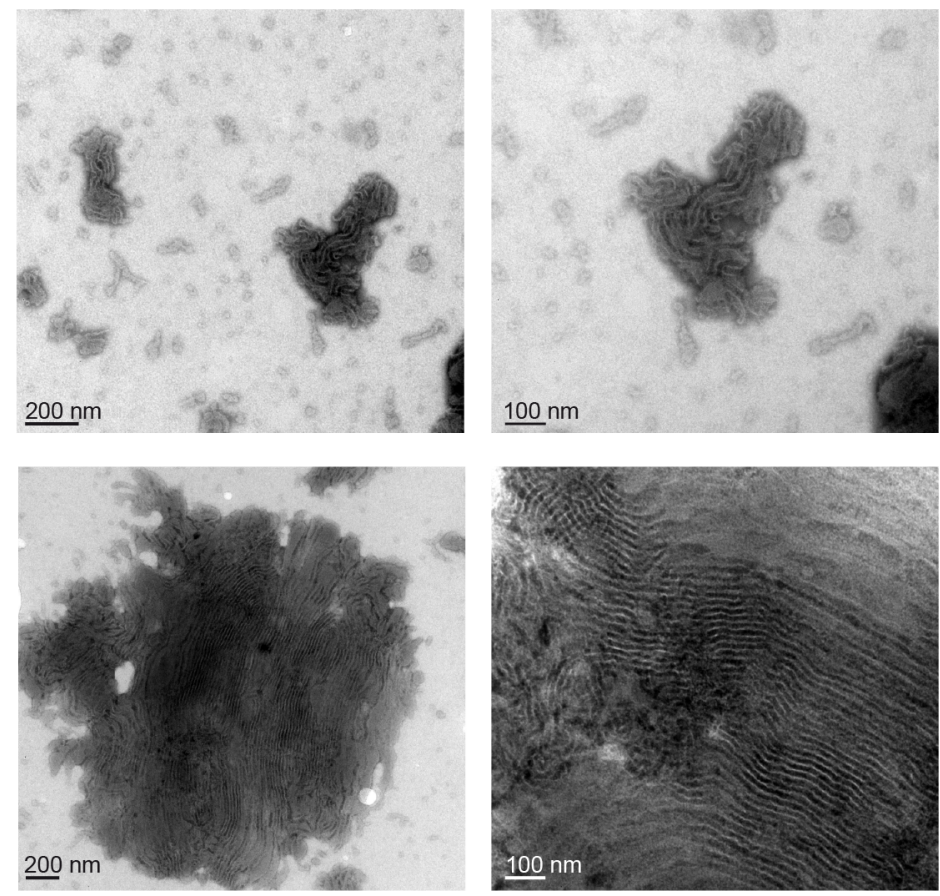

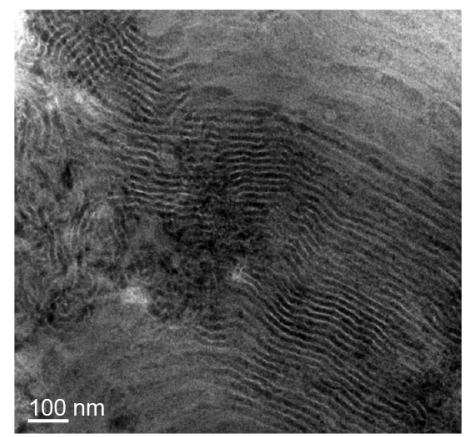

Figure 5. Reconstitution of BmrA by GRecon for a solid-state NMR sample. BmrA reconstituted in lipids by GRecon (A) and analyzed on a coomassie gel was characterized by TEM (B), which reveals the presence of the specific structural organization induced by BmrA reconstituted in the lipids. The top line in the coomassie gel, after the marker, corresponds to the sample load before centrifugation.

The layers containing the protein were collected and the material was sedimented at $100{ }^{\prime} 000$ $\mathrm{x} g$ during $1 \mathrm{~h}$ and washed 8 times in order to remove the sucrose. The protein in lipids obtained after GRecon was $1.8 \mathrm{mg}$ (yield of $60 \%$ ) from one tube. The activity of the protein in the presence of $10 \mathrm{mM} \mathrm{ATP}-\mathrm{Mg}^{2+}$ was measured at $2.2 \mu \mathrm{mol} \cdot \mathrm{min}^{-1} \cdot \mathrm{mg}^{-1}$. The sample was analyzed by MALDI-TOF mass spectrometry and showed no trace of DDM or Triton X-100 (Figure S8). As described in the literature ${ }^{14,22,24}$, tubular structures can be observed when BmrA is reconstituted in lipids with a LPR below 2. An EM analysis of two different proteincontaining fractions from a $1 \% \alpha$-cyclodextrin band allows the observation of tubular structures, as also observed by dialysis. Some dense structures resulting from a stacking of the tubular structures can be noticed (Figure 5B).

In order to fill a solid-state NMR rotor, the procedure was repeated with 12 tubes (corresponding to two centrifuge runs) for a run of $15 \mathrm{~h}$ resulting in a total of about $20 \mathrm{mg}$ protein. When comparing this to the 6 days $(144 \mathrm{~h})$ needed for dialysis, GRecon spares about an order magnitude in time. The protein pellet was loaded in a $3.2 \mathrm{~mm}$ solid-state NMR rotor 
using a rotor filling tool ${ }^{16}$. As can be seen in Figure 6, the chemical-shift dispersion and line widths of the BmrA samples prepared using dialysis and GRecon look very similar. We only noticed minor differences for GRecon reconstituted sample that might be due to a slightly different LPR, as also inferred from above data.
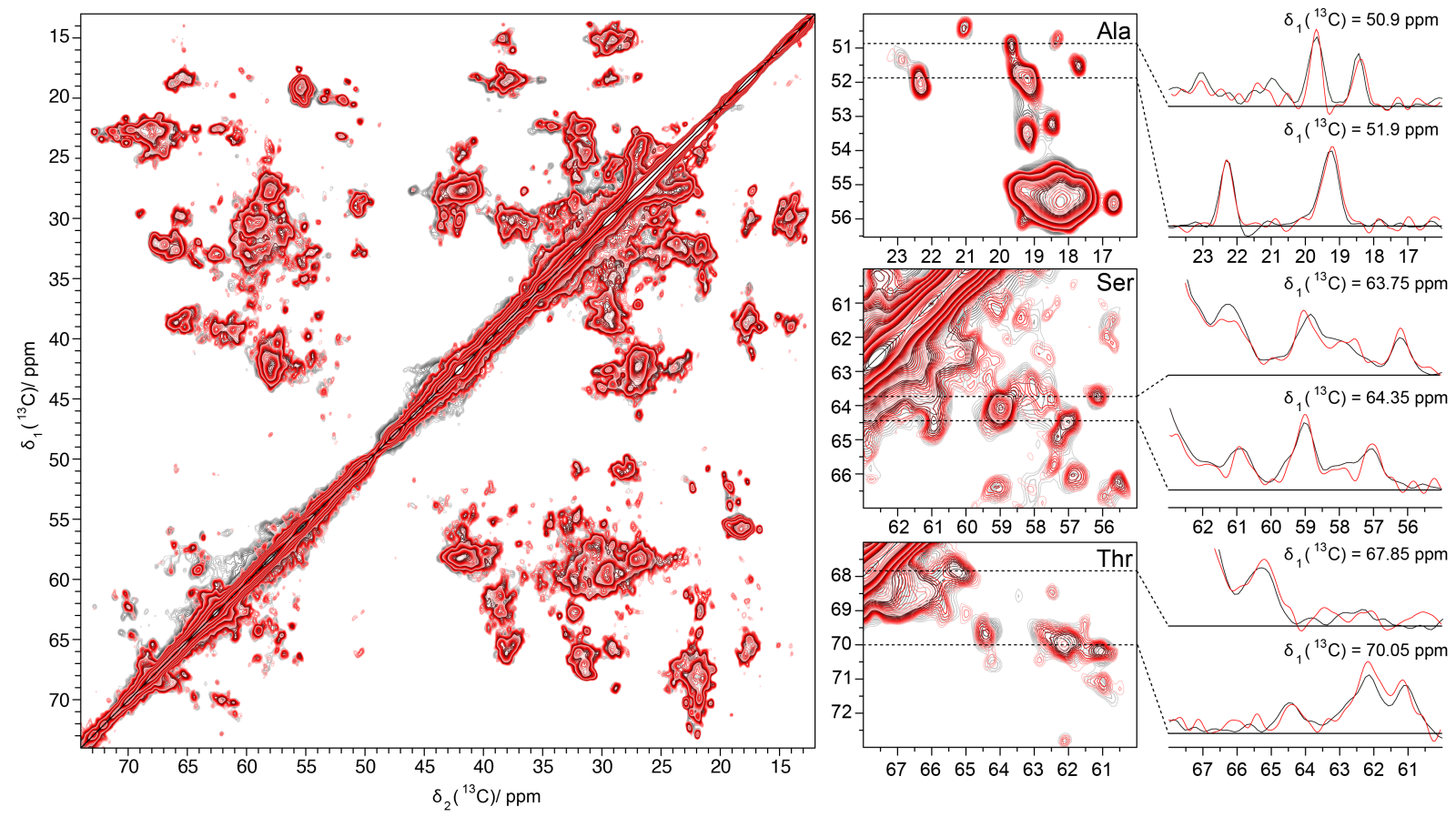

Figure 6. Extracts of a $2 \mathrm{D}{ }^{13} \mathrm{C}-{ }^{13} \mathrm{C} 20 \mathrm{~ms}$ DARR spectrum of lipid-reconstituted BmrA. The aliphatic region and a zoom of the Ala, Ser and Thr regions of reconstituted BmrA are shown, with the sample resulting from GRecon in red shades overlaid on dialysis-reconstituted BmrA in grey shades. Representative 1D traces along F2 are shown for both spectra. The individual spectra are shown in Figure S9.

\section{Conclusion}

We here analyzed how GRecon can be applied to solid-state NMR sample preparation of the $\mathrm{ABC}$ transporter BmrA, and propose procedures which shall be generally applicable for the reconstitution of membrane protein NMR samples. We established optimal concentrations of lipids and cyclodextrin in the gradient, for both small- and large-scale reconstitution. The up scaling allows us to reconstitute around $20 \mathrm{mg}$ of protein by two centrifuge runs. The use of GRecon reduced the reconstitution time by about an order of magnitude, and yielded similar NMR spectra as the dialysis method. The resulting gain in time might be crucial in the context of proteins which prove unstable during the long reconstitution times needed when using dialysis. For both cases, the spectra displayed an optimal signal-to-noise ratio and stable 
samples. Compared to the dialysis reconstitution, the yield was $60 \%$ in GRecon. The developed method shall show its highest potential when a variety of samples are produced for screening of different functional states, combined with fast MAS approaches asking for small sample quantities.

\section{Acknowledgment}

This work was supported by the French ANR (ANR-14-CE09-0024B), the LABEX ECOFECT (ANR-11-LABX-0048) within the Université de Lyon program Investissements d'Avenir (ANR-11-IDEX-0007), by the Swiss National Science Foundation (Grant 200020_159707), and the TH program of ETH Zürich (ETH-45 13-2). We acknowledge the contribution of SFR Biosciences (UMS3444/CNRS, US8/Inserm, ENS de Lyon, UCBL) facilities and the staff of Protein Science Facility, especially Frédéric Delolme, as well as the CIQLE facility Lyon.

\section{References}

1. Wallin, E. \& Heijne, von, G. Genome-wide analysis of integral membrane proteins from eubacterial, archaean, and eukaryotic organisms. Protein Sci. 7, 1029-1038 (1998).

2. Arinaminpathy, Y., Khurana, E., Engelman, D. M. \& Gerstein, M. B. Computational analysis of membrane proteins: the largest class of drug targets. Drug Discov. Today 14, 1130-1135 (2009).

3. Bakheet, T. M. \& Doig, A. J. Properties and identification of human protein drug targets. Bioinformatics 25, 451-457 (2009).

4. Bull, S. C. \& Doig, A. J. Properties of protein drug target classes. PLoS ONE 10, e0117955 (2015).

5. International Transporter Consortium et al. Membrane transporters in drug development. Nat Rev Drug Discov 9, 215-236 (2010).

6. Wang, S. \& Ladizhansky, V. Recent advances in magic angle spinning solid state NMR of membrane proteins. Progress in Nuclear Magnetic Resonance Spectroscopy 82, 1-26 (2014).

7. Alvarez, F. J. D. et al. Full engagement of liganded maltose-binding protein stabilizes a semi-open ATP-binding cassette dimer in the maltose transporter. Mol. Microbiol. 98, 878-894 (2015).

8. Rigaud, J. L., Pitard, B. \& Levy, D. Reconstitution of membrane proteins into 
liposomes: application to energy-transducing membrane proteins. Biochim. Biophys. Acta 1231, 223-246 (1995).

9. Seddon, A. M., Curnow, P. \& Booth, P. J. Membrane proteins, lipids and detergents: not just a soap opera. 1666, 105-117 (2004).

10. Rigaud, J. L. et al. Bio-Beads: an efficient strategy for two-dimensional crystallization of membrane proteins. Journal of Structural Biology 118, 226-235 (1997).

11. DeGrip, W. J., Vanoostrum, J. \& Bovee-Geurts, P. H. Selective detergent-extraction from mixed detergent/lipid/protein micelles, using cyclodextrin inclusion compounds: a novel generic approach for the preparation of proteoliposomes. Biochem. J. 330 ( Pt 2), 667-674 (1998).

12. Althoff, T., Davies, K. M., Schulze, S., Joos, F. \& Kühlbrandt, W. GRecon: A Method for the Lipid Reconstitution of Membrane Proteins. Angew. Chem. Int. Ed. 51, 83438347 (2012).

13. Steinfels, E. et al. Characterization of $\mathrm{YvcC}(\mathrm{BmrA})$, a Multidrug ABC Transporter Constitutively Expressed in Bacillus subtilis $\uparrow$. Biochemistry 43, 7491-7502 (2004).

14. Kunert, B. et al. Efficient and stable reconstitution of the $\mathrm{ABC}$ transporter BmrA for solid-state NMR studies. Front Mol Biosci 1, 5 (2014).

15. Studier, F. W. Protein production by auto-induction in high-density shaking cultures. Protein Expression and Purification 41, 207-234 (2005).

16. Böckmann, A. et al. Characterization of different water pools in solid-state NMR protein samples. J Biomol NMR 45, 319-327 (2009).

17. Chaptal, V. et al. Quantification of Detergents Complexed with Membrane Proteins. Sci Rep 7, 41751 (2017).

18. Doerrler, W. T. \& Raetz, C. R. H. ATPase activity of the MsbA lipid flippase of Escherichia coli. Journal of Biological Chemistry 277, 36697-36705 (2002).

19. Stevens, T. J. et al. A software framework for analysing solid-state MAS NMR data. $J$ Biomol NMR 51, 437-447 (2011).

20. Orelle, C., Dalmas, O., Gros, P., Di Pietro, A. \& Jault, J.-M. The conserved glutamate residue adjacent to the Walker-B motif is the catalytic base for ATP hydrolysis in the ATP-binding cassette transporter BmrA. Journal of Biological Chemistry 278, 4700247008 (2003).

21. Yang, Z. et al. Membrane protein stability can be compromised by detergent interactions with the extramembranous soluble domains. Protein Sci. 23, 769-789 (2014). 
22. Orelle, C. et al. Conformational change induced by ATP binding in the multidrug ATPbinding cassette transporter BmrA. Biochemistry 47, 2404-2412 (2008).

23. De Foresta, B., Le Maire, M., Orlowski, S. \& Champeil, P. Membrane solubilization by detergent: use of brominated phospholipids to evaluate the detergent-induced changes in Ca2+-ATPase/lipid interaction. Biochemistry 28, 2558-2567 (1989).

24. Fribourg, P.-F. et al. 3D cryo-electron reconstruction of BmrA, a bacterial multidrug $\mathrm{ABC}$ transporter in an inward-facing conformation and in a lipidic environment. $J$. Mol. Biol. 426, 2059-2069 (2014).

25. Hauer, F. et al. GraDeR: Membrane Protein Complex Preparation for Single-Particle Cryo-EM. Structure 23, 1769-1775 (2015).

26. Coombs, D. H. \& Watts, N. R. Generating sucrose gradients in three minutes by tilted tube rotation. Anal. Biochem. 148, 254-259 (1985).

27. Ravaud, S. et al. The ABC transporter BmrA from Bacillus subtilis is a functional dimer when in a detergent-solubilized state. Biochem. J. 395, 345 (2006).

28. Agarwal, V. et al. De novo 3D structure determination from sub-milligram protein samples by solid-state $100 \mathrm{kHz}$ MAS NMR spectroscopy. Angew. Chem. Int. Ed. Engl. 53, 12253-12256 (2014). 


\section{Supporting information for:}

\section{Gradient reconstitution of membrane proteins for solid-state NMR studies}

Denis Lacabanne ${ }^{1}$, Alons Lends ${ }^{2}$, Clément Danis ${ }^{1}$, Britta Kunert ${ }^{1}$, Marie-Laure Fogeron ${ }^{1}$,

Vlastimil Jirasko $^{2}$, Claire Chuilon ${ }^{1}$, Lauriane Lecoq ${ }^{1}$, Cédric Orelle ${ }^{1}$, Vincent Chaptal ${ }^{1}$, Pierre Falson $^{1}$, Jean-Michel Jault ${ }^{1}$, Beat H. Meier ${ }^{2 *}$, and Anja Böckmann ${ }^{1 *}$

${ }^{1}$ Molecular Microbiology and Structural Biochemistry, Labex Ecofect, UMR 5086 CNRS-

Université de Lyon, IBCP, 7 passage du Vercors, 69367 Lyon, France

${ }^{2}$ Physical Chemistry, ETH Zurich, Vladimir-Prelog-Weg 2, 8093 Zurich, Switzerland

\begin{tabular}{|c|c|}
\hline Experiment & DARR \\
\hline MAS frequency $/ \mathrm{kHz}$ & 17 \\
\hline Field/T & 20 \\
\hline Transfer I & $\mathrm{HC}-\mathrm{CP}$ \\
\hline${ }^{1} \mathrm{H}$ field $/ \mathrm{kHz}$ & 67 \\
\hline${ }^{13} \mathrm{C}$ field $/ \mathrm{kHz}$ & 50 \\
\hline Shape & Tangent ${ }^{1} \mathrm{H}$ \\
\hline Time/ms & 0.65 \\
\hline Transfer II & DARR \\
\hline${ }^{1} \mathrm{H}$ field $/ \mathrm{kHz}$ & 17 \\
\hline Time/ms & 20 \\
\hline$t_{1}$ increments & 2048 \\
\hline Windows function & QSine 3 \\
\hline Sweep width $\left(\mathrm{t}_{1}\right) / \mathrm{kHz}$ & 100 \\
\hline Acquisition time $\left(\mathrm{t}_{1}\right) / \mathrm{ms}$ & 10 \\
\hline$t_{2}$ increments & 3072 \\
\hline Windows function & QSine 3 \\
\hline Sweep width $\left(t_{2}\right) / \mathrm{kHz}$ & 100 \\
\hline Acquisition time $\left(\mathrm{t}_{2}\right) / \mathrm{ms}$ & 15 \\
\hline${ }^{1} \mathrm{H}$ SPINAL64 decoupling power $/ \mathrm{kHz}$ & 90 \\
\hline Interscan delay/s & 2.6 \\
\hline Number of scans & 32 \\
\hline Measurement time/h & 48 \\
\hline
\end{tabular}

Table S1 Overview of experimental parameters of performed MAS NMR experiments 


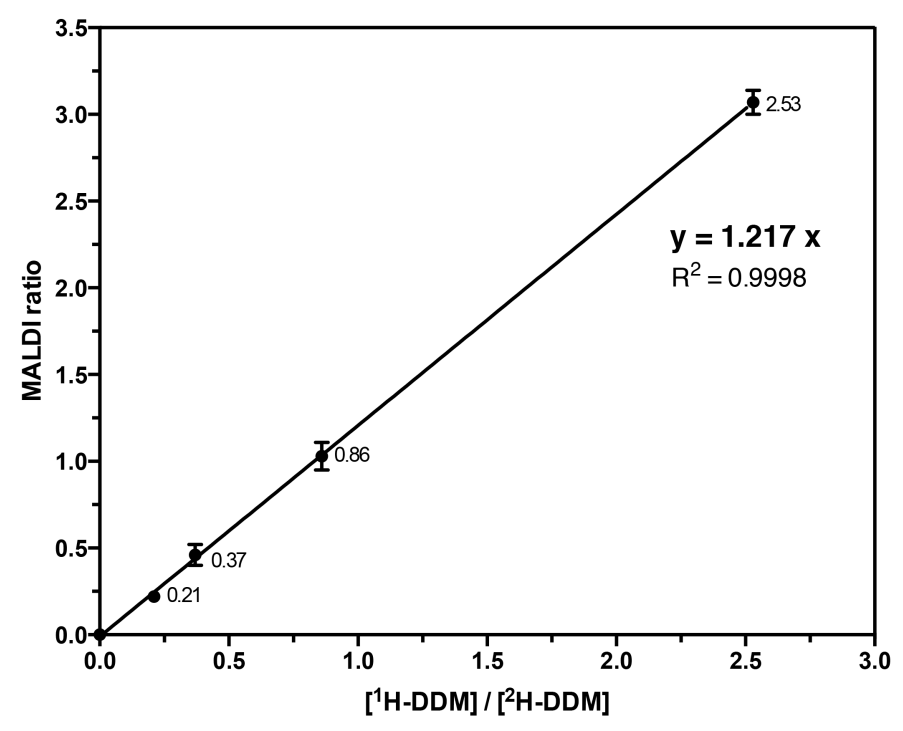

\begin{tabular}{|c|c|c|c|c|}
\hline Sample & $\mathbf{1 / 5}$ & $\mathbf{1 / 2}$ & $\mathbf{1 / 1}$ & $\mathbf{3 / 1}$ \\
\hline${ }^{1} \mathrm{H}$-DDM (\%) & 0.0055 & 0.011 & 0.024 & 0.071 \\
\hline${ }^{2} \mathrm{H}$-DDM (\%) & 0.027 & 0.028 & 0.028 & 0.028 \\
\hline Ratio & 0.21 & 0.37 & 0.86 & 2.53 \\
\hline MALDI ratio & 0.22 & 0.46 & 1.03 & 3.07 \\
\hline MALDI error & 0.03 & 0.06 & 0.08 & 0.07 \\
\hline
\end{tabular}

Figure S1. Calibration curve for DDM quantification using ${ }^{2} \mathrm{H}-\mathrm{DDM}$ as internal standard.

The theoretical ratios are plotted against the experimental ratios (MALDI ratios) obtained by MALDI-TOF. Each ${ }^{1} \mathrm{H} /{ }^{2} \mathrm{H}$ ratio is indicated on the plot. The experiment was done in triplicate and the fit follows a linear regression (done using GraphPad Prism). 

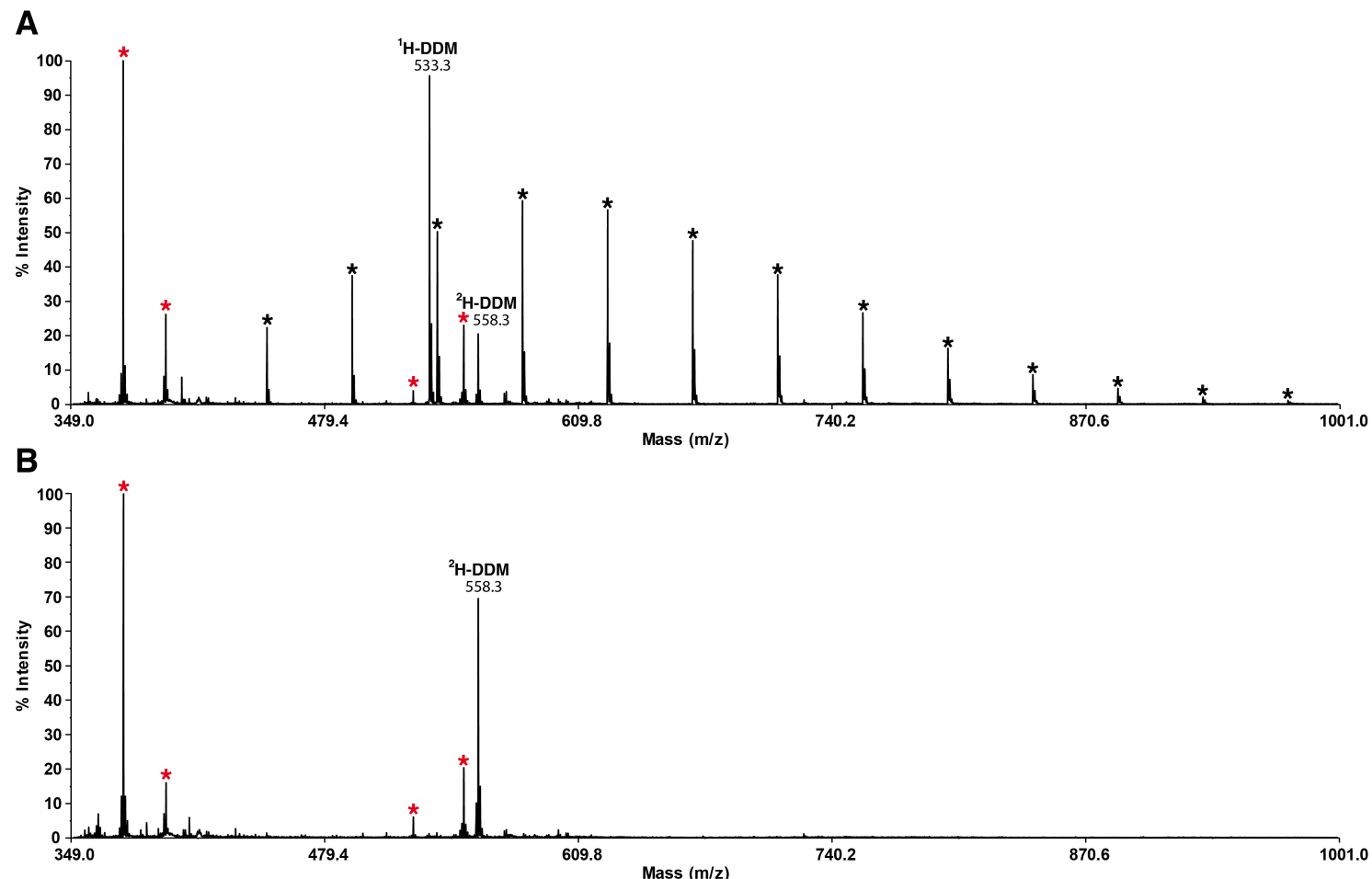

Figure S2. Mass Spectrometry analysis of BmrA before and after dialysis. (A) Mass Spectrometry profile of BmrA in $0.05 \%$ DDM with B. subtilis lipids destabilized by $0.15 \%$ Triton X-100 before reconstitution by dialysis. (B) Mass Spectrometry spectrum of BmrA in B. subtilis lipids after reconstitution by dialysis (6 days). Peaks from ${ }^{1} \mathrm{H}-\mathrm{DDM}$ and Triton $\mathrm{X}$ 100 are absents after 9 days of reconstitution. ${ }^{2} \mathrm{H}$-DDM standard was used in both samples in order to quantify the DDM presents in the sample. Black stars indicate the peaks corresponding to Triton X-100, red stars indicate the dihydroxybenzoic acid used as matrix substance for MALDI-MS. 

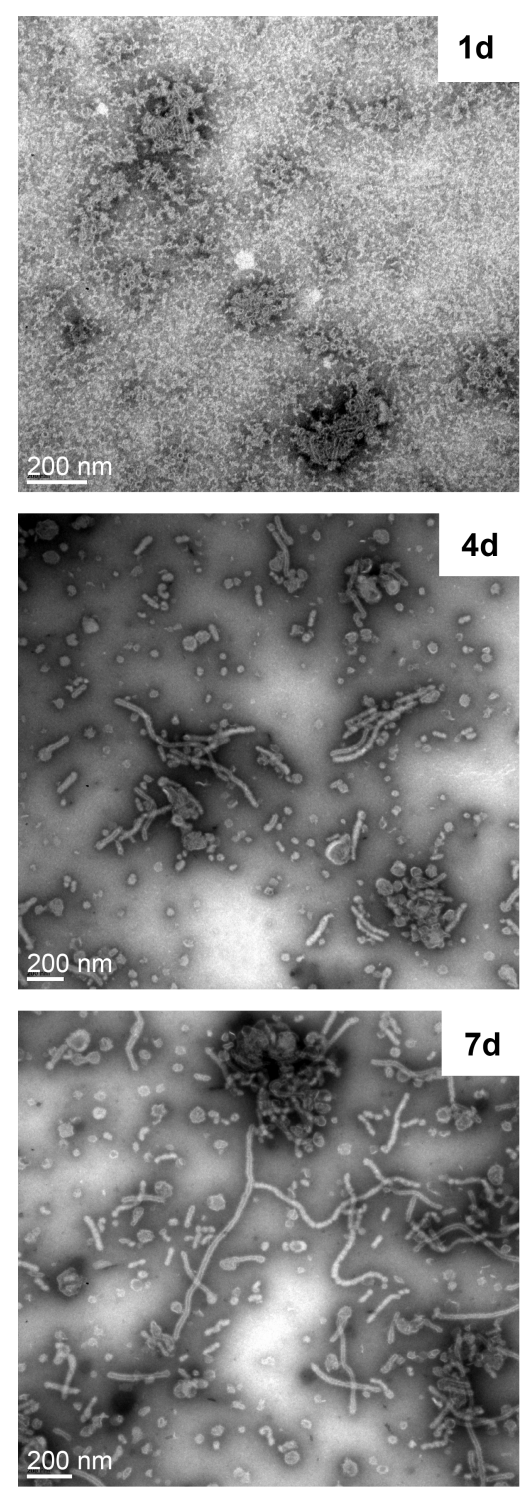
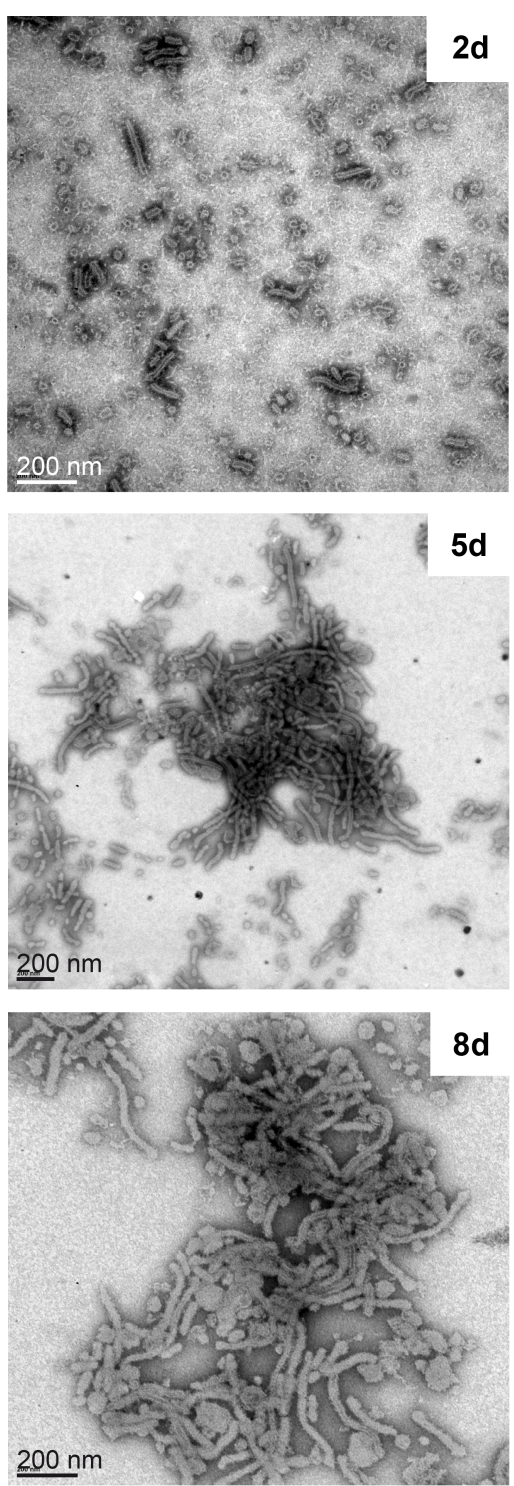
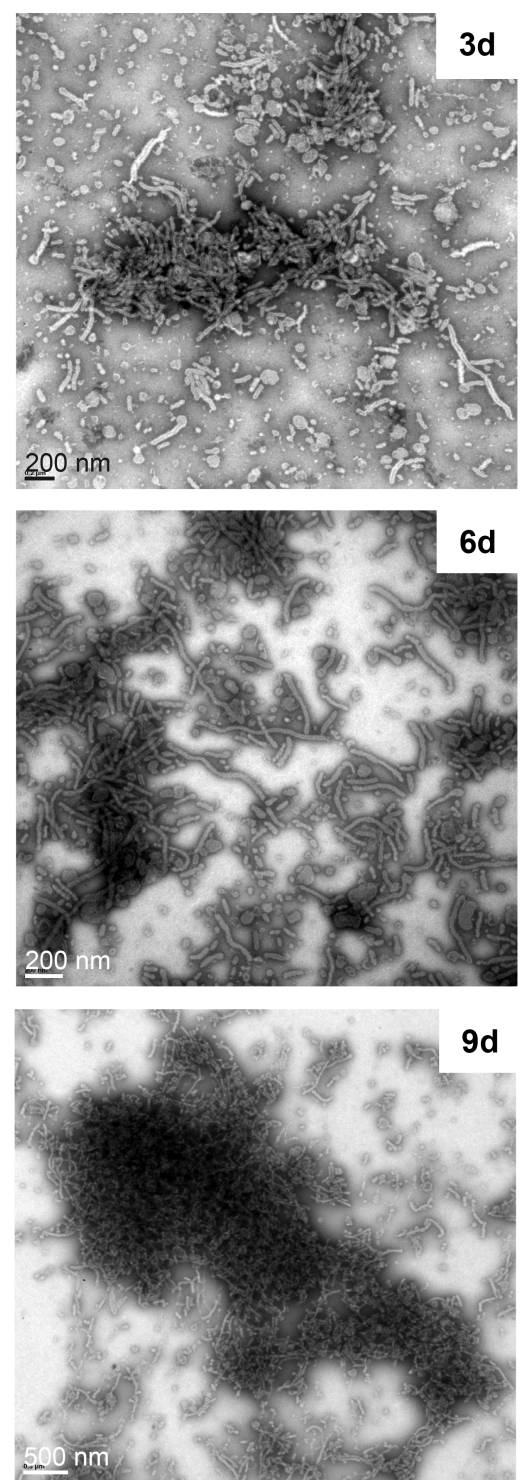

Figure S3: Electron microscopy images of BmrA recorded during reconstitution by

dialysis. The samples correspond to the data points shown in Figure 1A and were collected directly from the dialysis bag each day and deposited on a 300-mesh Cu-Formvar grid, and subsequently negatively stained with $2 \%$ phosphotungstic acid. 


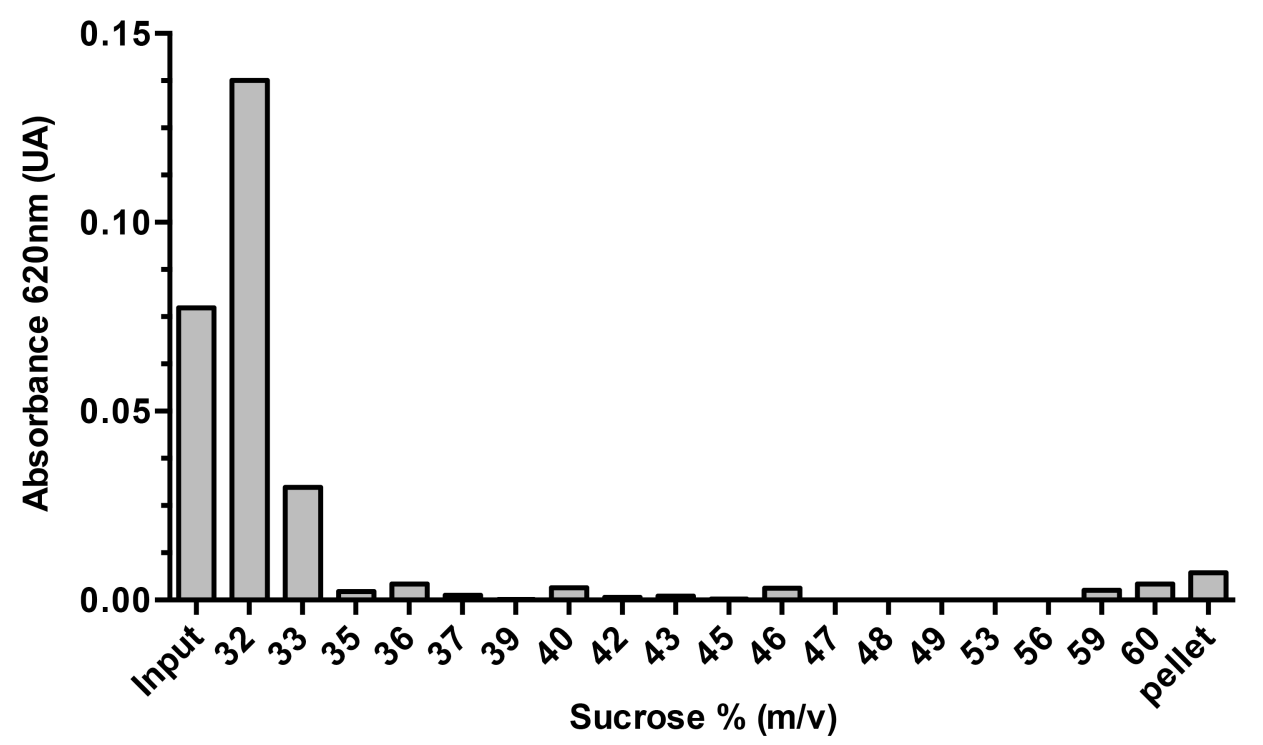

Figure S4: DDM distribution inside a 30-60\% sucrose gradient. We used a coomassie (Bradford) protein assay kit (Thermo Scientific ${ }^{\mathrm{TM}}$ ) to probe the presence of DDM inside a 30$60 \%$ sucrose gradient. Indeed, it is well-known that colorimetric dyes in protein assay kits can be altered by the presence of detergent. The detergent interaction with the colorimetric dye can be used in order to determine the presence or the quantity of $\mathrm{DDM}^{1}$. In a microplate, 100 $\mu \mathrm{L}$ of gradient layer were mixed with $10 \mu \mathrm{L}$ of a coomassie (Bradford) protein assay kit (Thermo Scientific ${ }^{\mathrm{TM}}$ ). The absorbance was read at $620 \mathrm{~nm}$ (Infinite M1000 Tecan Group Ltd). 


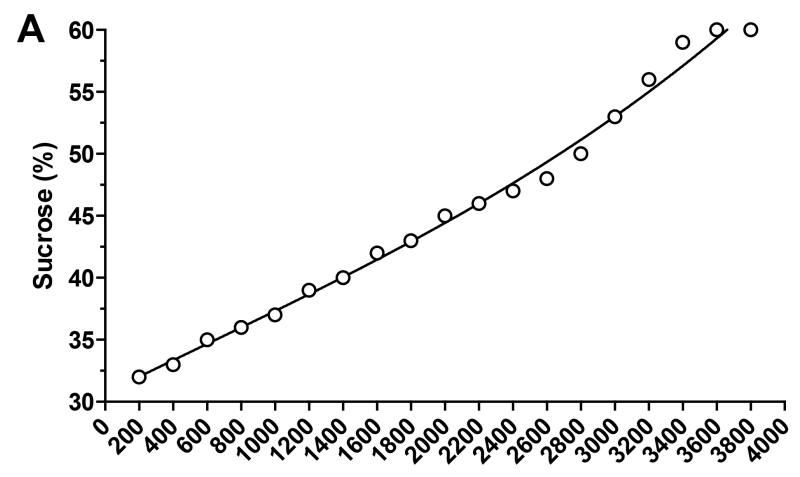

SW60 Gradient volumes $(\mu \mathrm{L})$

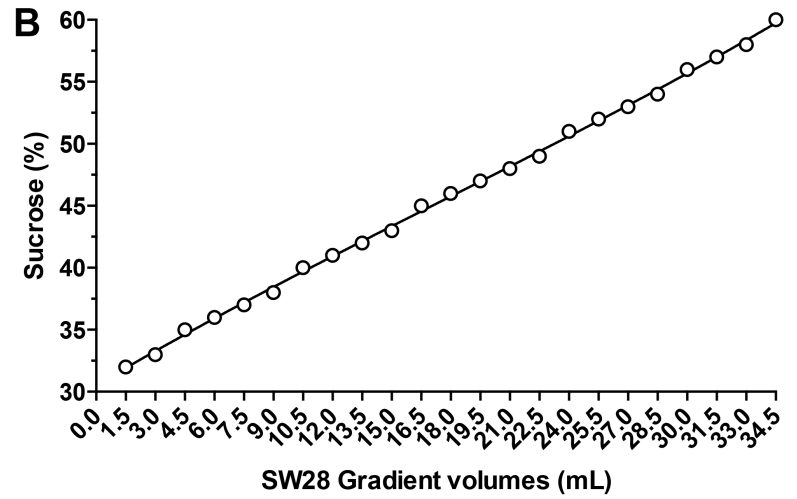

SW28 Gradient volumes $(\mathrm{mL})$

Figure S5: Sucrose concentration of each layer of gradients 30-60\% SW60 and SW28.

In order to determine the best gradient and also the sucrose concentration in each layer, a protocol using coomassie blue, described in the literature ${ }^{2}$ and by the manufacturer (BioComp Instruments, Inc), was used. Two layers containing 30\% and $60 \%$ sucrose were initially laid in the centrifuge tube. The lower solution contains equally $0.30 \%$ of Coomassie ${ }^{\circledR}$-brilliant blue R250. Then, the upper and the lower solutions were mixed with the Gradient Master ${ }^{\mathrm{TM}}$ in order to obtain a continuous gradient. For the evaluation of gradients, the absorbance at 820 $\mathrm{nm}$ was determined for layers of $200 \mu \mathrm{L}$ (SW60) and $1.5 \mathrm{~mL}$ (SW28). The profile obtained was converted to sucrose concentration as shown by Coombs and Watts ${ }^{2}: C_{i}=(X-y) d_{i}+y$, with $\mathrm{C}_{\mathrm{i}}$ the sucrose concentration at point $\mathrm{I}, \mathrm{X}$ the heavy sucrose concentration $(60 \%)$, y the light concentration of sucrose and $\mathrm{d}_{\mathrm{i}}$ the absorbance of the layer. 


\begin{tabular}{|c|c|c|c|c|c|c|}
\hline \multicolumn{7}{|c|}{ SW60 } \\
\hline \multirow{2}{*}{ Layers $(\boldsymbol{\mu l}$ ) } & \multirow{2}{*}{ Sucrose (\%) } & \multicolumn{5}{|c|}{ Cumulative $\mathbf{\alpha - c y c l o d e x t r i n ~ ( n m o l ) ~}$} \\
\cline { 3 - 7 } & & $\mathbf{0 - 0 . 2 5 \%}$ & $\mathbf{0 - 0 . 5 0 \%}$ & $\mathbf{0 - 1} \%$ & $\mathbf{0 - 2} \%$ & $\mathbf{0 - 3} \%$ \\
\hline $\mathbf{2 0 0}$ & $\mathbf{3 2}$ & 50 & 70 & 150 & 250 & 400 \\
\hline $\mathbf{4 0 0}$ & $\mathbf{3 3}$ & 100 & 170 & 350 & 700 & 1050 \\
\hline $\mathbf{6 0 0}$ & $\mathbf{3 5}$ & 150 & 350 & 700 & 1350 & 2050 \\
\hline $\mathbf{8 0 0}$ & $\mathbf{3 6}$ & 250 & 550 & 1100 & 2200 & 3300 \\
\hline $\mathbf{1 0 0 0}$ & $\mathbf{3 7}$ & 400 & 800 & 1600 & 3150 & 4750 \\
\hline $\mathbf{1 2 0 0}$ & $\mathbf{3 9}$ & 550 & 1100 & 2200 & 4400 & 6600 \\
\hline $\mathbf{1 4 0 0}$ & $\mathbf{4 0}$ & 700 & 1450 & 2900 & 5750 & 8650 \\
\hline $\mathbf{1 6 0 0}$ & $\mathbf{4 2}$ & 950 & 1850 & 3700 & 7400 & 11100 \\
\hline $\mathbf{1 8 0 0}$ & $\mathbf{4 3}$ & 1150 & 2300 & 4600 & 9200 & 13750 \\
\hline $\mathbf{2 0 0 0}$ & $\mathbf{4 5}$ & 1400 & 2800 & 5600 & 11250 & 16850 \\
\hline $\mathbf{2 2 0 0}$ & $\mathbf{4 6}$ & 1700 & 3350 & 6700 & 13450 & 20150 \\
\hline $\mathbf{2 4 0 0}$ & $\mathbf{4 7}$ & 1950 & 3950 & 7900 & 15750 & 23650 \\
\hline $\mathbf{2 6 0 0}$ & $\mathbf{4 8}$ & 2300 & 4550 & 9100 & 18250 & 27350 \\
\hline $\mathbf{2 8 0 0}$ & $\mathbf{4 9}$ & 2600 & 5200 & 10400 & 20850 & 31250 \\
\hline $\mathbf{3 0 0 0}$ & $\mathbf{5 3}$ & 3000 & 6000 & 12000 & 24000 & 36000 \\
\hline $\mathbf{3 2 0 0}$ & $\mathbf{5 6}$ & 3450 & 6900 & 13750 & 27550 & 41300 \\
\hline $\mathbf{3 4 0 0}$ & $\mathbf{5 9}$ & 3950 & 7900 & 15750 & 31500 & 47300 \\
\hline $\mathbf{3 6 0 0}$ & $\mathbf{6 0}$ & 4450 & 8900 & 17800 & 35650 & 53450 \\
\hline $\mathbf{3 8 0 0}$ & $\mathbf{6 0}$ & 4950 & 9950 & 19850 & 39750 & 59600 \\
\hline
\end{tabular}

\begin{tabular}{|c|c|c|}
\hline \multicolumn{3}{|c|}{ SW32 } \\
\hline Layers (mI) & Sucrose (\%) & Cumulative $\boldsymbol{\alpha}$-cyclodextrin (nmol) \\
\hline $\mathbf{1 . 5}$ & $\mathbf{3 2}$ & 1050 \\
\hline $\mathbf{3}$ & $\mathbf{3 3}$ & 2550 \\
\hline $\mathbf{4 . 5}$ & $\mathbf{3 5}$ & 5150 \\
\hline $\mathbf{6}$ & $\mathbf{3 6}$ & 8200 \\
\hline $\mathbf{7 . 5}$ & $\mathbf{3 7}$ & 11800 \\
\hline $\mathbf{9}$ & $\mathbf{3 8}$ & 15950 \\
\hline $\mathbf{1 0 . 5}$ & $\mathbf{4 0}$ & 21050 \\
\hline $\mathbf{1 2}$ & $\mathbf{4 1}$ & 26750 \\
\hline $\mathbf{1 3 . 5}$ & $\mathbf{4 2}$ & 32900 \\
\hline $\mathbf{1 5}$ & $\mathbf{4 3}$ & 39600 \\
\hline $\mathbf{1 6 . 5}$ & $\mathbf{4 5}$ & 47300 \\
\hline $\mathbf{1 8}$ & $\mathbf{4 6}$ & 55500 \\
\hline $\mathbf{1 9 . 5}$ & $\mathbf{4 7}$ & 64250 \\
\hline $\mathbf{2 1}$ & $\mathbf{4 8}$ & 73500 \\
\hline $\mathbf{2 2 . 5}$ & $\mathbf{4 9}$ & 83250 \\
\hline $\mathbf{2 4}$ & $\mathbf{5 1}$ & 94050 \\
\hline $\mathbf{2 5 . 5}$ & $\mathbf{5 2}$ & 105350 \\
\hline $\mathbf{2 7}$ & $\mathbf{5 3}$ & 117200 \\
\hline $\mathbf{2 8 . 5}$ & $\mathbf{5 4}$ & 129500 \\
\hline $\mathbf{3 0}$ & $\mathbf{5 6}$ & 142900 \\
\hline $\mathbf{3 1 . 5}$ & $\mathbf{5 7}$ & 156750 \\
\hline $\mathbf{3 3}$ & $\mathbf{5 8}$ & 171150 \\
\hline $\mathbf{3 4 . 5}$ & $\mathbf{6 0}$ & 186550 \\
\hline & & \\
\hline
\end{tabular}

Figure S6: Parameter table of gradients used with SW60 and SW32. For each layer cumulative $\alpha$-cyclodextrin values in nmol are estimated considering the gradient determined previously (Figure S5). The closest value to the theoretical $900 \mathrm{nmol}$ of $\alpha$-cyclodextrin needed to strip detergent from $4.5 \mathrm{nmol}$ of $\mathrm{BmrA}$ is highlighted in red for each gradient. 

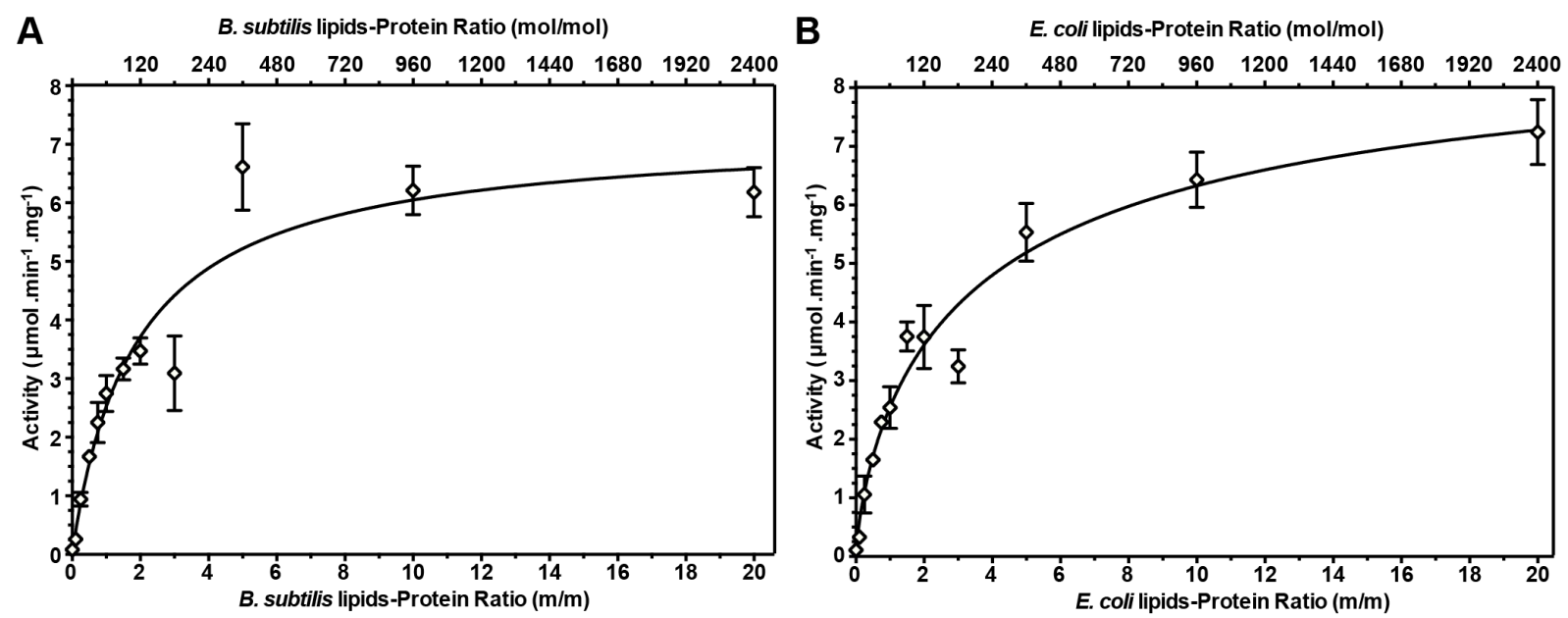

Figure S7: ATPase activity as a function of LPR. BmrA was reconstituted using different LPR between 0-20 and with lipids from A) B. subtilis (homemade preparation, see below) or B) E. coli lipids (Avanti ${ }^{\circledR}$ Polar Lipids, Inc). The ATPase activity was probed for the different LPRs and the different lipids in presence of $10 \mathrm{mM}$ ATP. The activity of BmrA in B. subtilis lipids follows the same trend as in E. coli lipids. In both cases, the activity increases with the LPR following a hyperbolic curve. The catalytic activity is slightly higher in E. coli lipids than in B. subtilis lipids. The maximum velocity of BmrA in presence of $10 \mathrm{mM}$ ATP and $B$. subtilis and E. coli lipids is estimated to $7.2 \pm 0.5$ and $9.4 \pm 0.9 \mu$ mol. $\mathrm{min}^{-1} . \mathrm{mg}^{-1}$ respectively. The fitting was done with GraphPad Prism 6.

The B. subtilis lipids homemade preparation was prepared as described in Kunert et al. ${ }^{3}$. Shortly, B. subtilis was cultivated in LB medium at $37^{\circ} \mathrm{C}$ during, until an $\mathrm{OD}_{600 \mathrm{~nm}}$ of 4. Bacteria were harvested by centrifugation, $6000 \times \mathrm{g}, 30 \mathrm{~min}$. For $10 \mathrm{~g}$ of pellet, $20 \mathrm{~mL}$ of chloroform and $40 \mathrm{~mL}$ of methanol were added directly with the pellet and the solution was incubated during $2 \mathrm{~h}$ at room temperature. After incubation, solid particles were removed by filtration. The filtrate was mixed with $20 \mathrm{~mL}$ chloroform and $20 \mathrm{~mL}$ water. The extraction was performed for 2 days in a separation funnel. The solvent of the lower phase containing chloroform and lipids was removed in a rotary evaporator followed by lyophilisation. The lipids were suspended in chloroform and stored at $-20^{\circ} \mathrm{C}$ for 1 month maximum. The final lipid amount was about $20 \mathrm{mg}$ per liter of B. subtilis culture. 


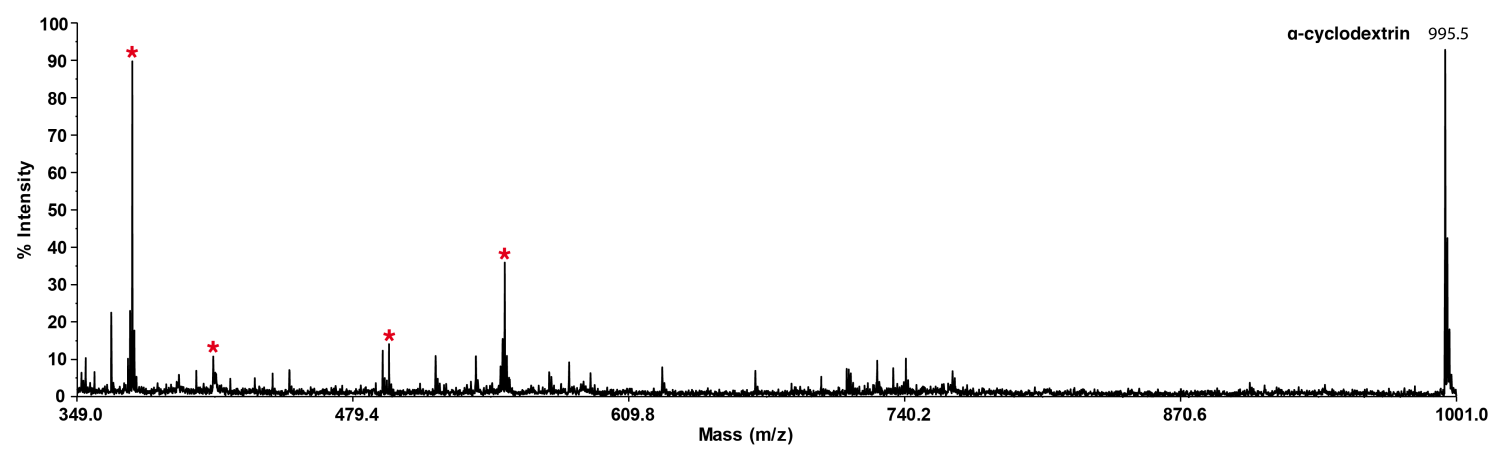

Figure S8. Mass Spectrometry analysis of BmrA after GRecon. Mass Spectrometry spectrum of BmrA in B. subtilis lipids after reconstitution by GRecon. The sample was diluted 100 times in the matrix in order to crystallize the deposit on the MALDI-target. The presence of DDM was not detected in MALDI-TOF. Red stars indicate the dihydroxybenzoic acid used as matrix substance for MALDI-MS. 

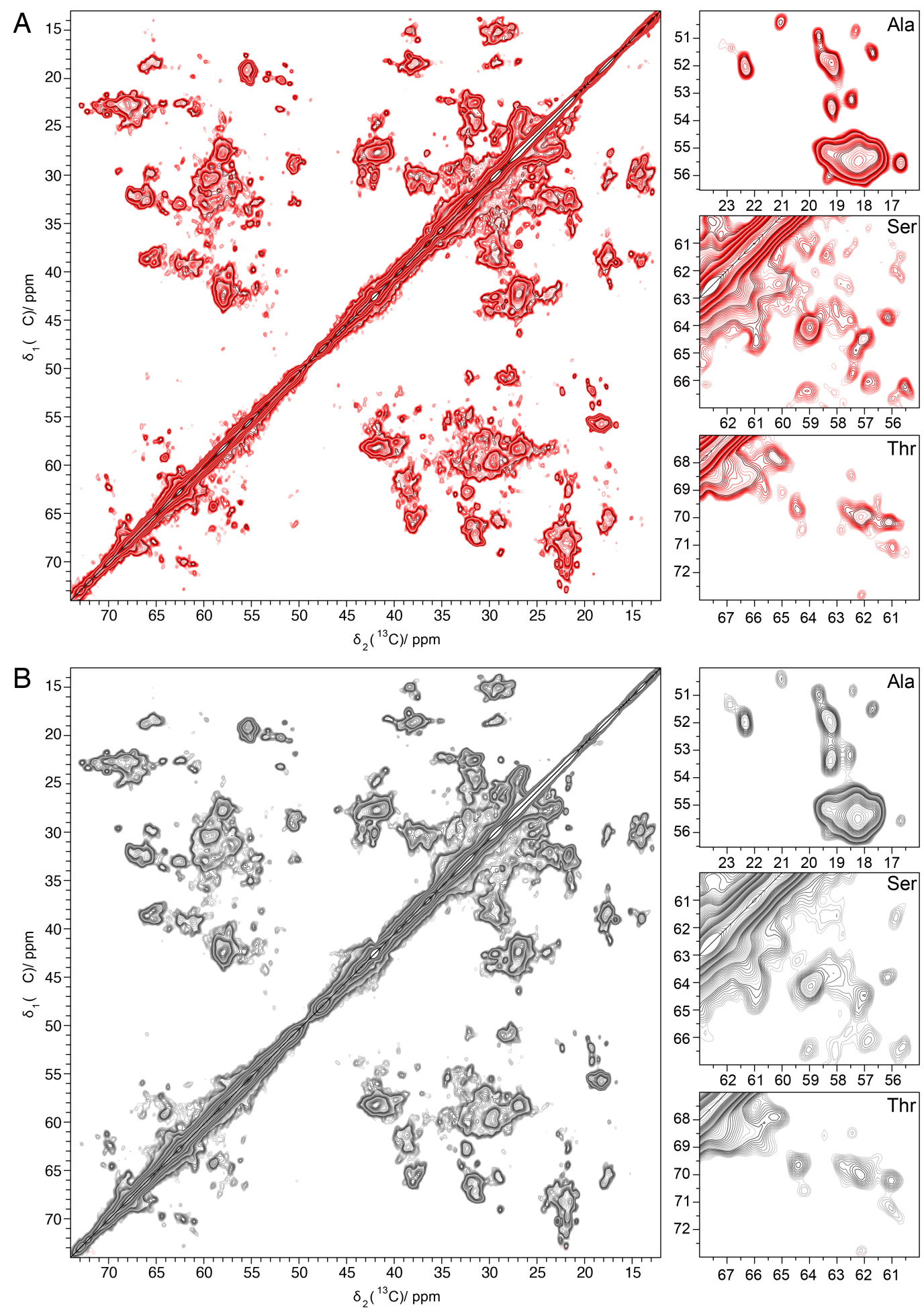

Figure S9. Extracts of a 2D ${ }^{13} \mathrm{C}-{ }^{13} \mathrm{C} 20 \mathrm{~ms}$ DARR spectrum of lipid-reconstituted BmrA.

The aliphatic region and a zoom of the Ala, Ser and Thr regions of reconstituted BmrA are shown, with the sample resulting from GRecon in red shades (A) and from dialysisreconstituted BmrA in grey shades $(\mathbf{B})$. 
1. Ostuni, M. A., Iatmanen, S., Teboul, D., Robert, J.-C. \& Lacapère, J.-J. in Membrane Protein Structure Determination (ed. Lacapère, J.-J.) 654, 3-18 (Humana Press, 2010).

2. Coombs, D. H. \& Watts, N. R. Generating sucrose gradients in three minutes by tilted tube rotation. Anal. Biochem. 148, 254-259 (1985).

3. Kunert, B. et al. Efficient and stable reconstitution of the ABC transporter BmrA for solid-state NMR studies. Front Mol Biosci 1, 5 (2014). 